\title{
Electromagnetic Effects on Solidification Defect Formation in Continuous Steel Casting
}

\author{
SEONG-MOOK $\mathrm{CHO}^{1}$ and BRIAN G. THOMAS (1) ${ }^{1,2}$ \\ 1.-Colorado School of Mines, Department of Mechanical Engineering, Brown Hall W470I, 1610 \\ Illinois Street, Golden, CO 80401, USA. 2.—e-mail: bgthomas@mines.edu
}

Understanding and reducing defects formed during continuous casting of steel are challenging because of the many inter-related, multiscale phenomena and process parameters involved in this complex process. Solidification occurs in the presence of turbulent multiphase flow, transport and capture of particles, superheat transport, and thermal-mechanical behavior. The application of electromagnetic fields provides an additional parameter to control these phenomena to reduce solidification defects. It is especially attractive because the field has the potential to be easily adjusted during casting to accommodate different casting conditions. This article briefly reviews how electromagnetic forces affect solidification defects, including subsurface hooks, particle capture, deep oscillation marks, depressions, cracks, breakouts, segregation, and shrinkage. This includes the related effects on superheat transport, initial solidification, surface quality, grain structure, internal quality, and steel composition distribution. Finally, some practical strategies regarding how to apply electromagnetics to improve steel quality are evaluated.

\section{INTRODUCTION}

Continuous casting is the most widely used process to manufacture steel, accounting for $>96 \%$ of steel in the world. ${ }^{1}$ Thus, even small improvements to this process can greatly impact the industry. During continuous casting, molten steel flows into the mold cavity through a submerged nozzle and freezes against the water-cooled mold plates in the presence of turbulent fluid flow, argon gas injection, transport and capture of particles, superheat transport, and thermal-mechanical behavior, ${ }^{2-4}$ and it finally solidifies into a semi-finished solid shape, such as a slab, bloom, or billet. ${ }^{5}$ Solidification in this process is very complex and is difficult to understand and optimize, owing to the complicated behavior of the steel and slag 6,7 and the many process conditions that can be varied, such as nozzle geometry, mold size, casting speed, argon gas injection rate, water cooling conditions, and mold taper, in addition to the electromagnetic systems. Moreover, solidification defects are mainly caused

(Received May 17, 2020; accepted August 11, 2020;

published online September 3, 2020) by abnormal transient upsets of the various phenomena during casting. This makes it challenging to quickly detect and adequately respond to defect formation during operation.

Recent efforts involving improved sensing capabilities are enabling better monitoring of temperature of the mold plates, top surface, heat flux in the gap between the steel shell and mold, meniscus level variations, and slag consumption rate with the aid of thermocouples, ${ }^{8}$ fiber Bragg gratings, ${ }^{9,10}$ and other instantaneous sensing and recording systems. However, it is difficult to respond instantaneously because most process parameters are difficult to control during operation. Mold taper, ${ }^{11,12}$ spray cooling, ${ }^{13,14}$ and soft reduction systems ${ }^{15,16}$ are often set before starting casting and focus on steady-state solidification. Corrective action, such as responding to alarms from online breakout detection systems, for example, typically involve suddenly slowing the casting speed, which can lead to quality problems due to the transient conditions. For example, the slowdown produces a thicker region in the solidifying steel shell, leading to an entrapped liquid pocket towards final solidification, which may cause centerline bridging and segregation. $^{17}$ 
The application of electromagnetic fields to continuous casting is attractive to control solidificationrelated phenomena due to its capability of being easily adjusted during operation. Magnetic fields applied to the molten steel pool induce currents, which interact with the magnetic field to generate Lorentz forces in the opposite direction of the molten steel velocity and alter the flow pattern. Electromagnetic systems for steel continuous casting include static, moving or combined fields, and their strength depends on the locations and numbers of magnets, field frequencies (for moving fields), and, most importantly, the applied current. This has the potential for comprehensive online control of the molten steel flow, which is responsible for many solidification defects, through its effects on superheat transport, initial solidification, particle transport and capture, surface quality, grain structure, and steel composition distribution. ${ }^{18}$

This article reviews the various solidification defects in continuous casting and their formation mechanisms. It then focuses on the effects of electromagnetic fields on the solidification-related phenomena, which influence the formation of these defects. Finally, some practical strategies to implement electromagnetic operations are discussed.

\section{SOLIDIFICATION DEFECTS IN CONTINUOUS STEEL CASTING}

Solidification defects detrimental to the quality of final steel products include meniscus freezing and hooks, particle capture defects, deep oscillation marks, depressions and cracks, breakouts, and segregation.

\section{Meniscus Freezing and Hooks}

Superheat is transported by the molten steel flow to the solidification front, as shown in Fig. 1. The transport of superheat to the meniscus region around the top of the mold greatly influences initial solidification, which includes the infiltration behavior of the mold slag. Fluid flow across the top surface also influences local turbulence in the surface slag, which affects its melting rate, thickness of the liquid slag layer, and the surface profile (standing wave), which influences slag infiltration into the gap between the steel shell and the mold. Excessive surface flow causes both liquid level fluctuations and slag entrainment, ${ }^{19,20}$ leading to both surface and internal defects. Insufficient superheat delivered to the meniscus must also be avoided because it can lead to meniscus freezing, lubrication problems due to insufficient slag infiltration, and the formation of deep hooks. ${ }^{21,22}$ Deep hooks and lubrication problems lead to non-uniform heat transfer across the interfacial gap, and nonuniform growth of the solidifying steel, resulting in surface cracks and/or breakout formation. Overflow of the frozen meniscus during each oscillation cycle may entrap slag and lead to a line in the microstructure, which persists through two phase transformations to ambient temperature as shown in Fig. 2..$^{21-23}$ This is most likely near the corners of the mold, where the frozen meniscus hooks are deepest. ${ }^{23}$ The other side of the curved shape of the solidified meniscus acts as a hook to entrap mold slag, inclusions, and inclusion-laden argon bubbles, which lead to surface sliver defects in the final product.

On the other hand, excessive superheat transported by a downward directed steel jet towards the solidifying steel shell near mold exit can slow the steel shell growth on the mold walls. Figure 3 shows solidifying steel shell profiles on narrow faces (east and west) and wide faces (inside radius: IR; outside radius: OR) of the mold, including both plant measurements (symbols) and CON1D model ${ }^{24}$ calculations (lines). The steel shell on the narrow faces is clearly thinner than the shell on the wide faces, especially near the jet impingement point ( $300 \mathrm{~mm}$ below the meniscus), due to more superheat causing some erosion of the steel shell erosion. If there is also a problem with mold taper, then this shell thinning can lead to a breakout. ${ }^{25}$ It is also important to note that the steel shell profiles are asymmetric between the faces, which indicates that transient variations in fluid flow and superheat transport in the mold strongly affects the steel shell growth.

\section{Particle Capture Defects}

Particles including argon gas bubbles injected to prevent nozzle clogging, ${ }^{28}$ entrained slag droplets due to abnormal high surface velocity and/or severe surface level fluctuations, ${ }^{29,30}$ and alumina inclusions flowing into the mold cavity from upstream processes, such as ladle and tundish processes, ${ }^{31}$ may be entrapped by the solidifying steel shell, as shown in Fig. 4. The captured particles may become defects such as blisters and/or slivers in the final steel product if their capture locations are too deep to be removed by scale formation or scarfing processing. ${ }^{32}$

Particles contacting the steel shell may be entrapped in the three ways: (1) entrapment by solidified hooks near the meniscus, (2) entrapment between the primary dendrite arms, if the particles are smaller than the primary dendrite arm spacing (PDAS), and (3) engulfment, if larger particles stay in contact with the solidification long enough to become surrounded by the growing dendrites. ${ }^{33,34}$ Engulfment is only possible if the flow is sufficiently stagnant that the tangential forces acting on the particle balance long enough to prevent the particle at the shell front from being washed away back into the liquid pool. ${ }^{33,34}$ The formation of meniscus hooks, leading to particle capture near the meniscus, was discussed in the previous section. The second mechanism, involving the entrapment of small particles carried by the steel flow to the solidification front, depends on the number of small 


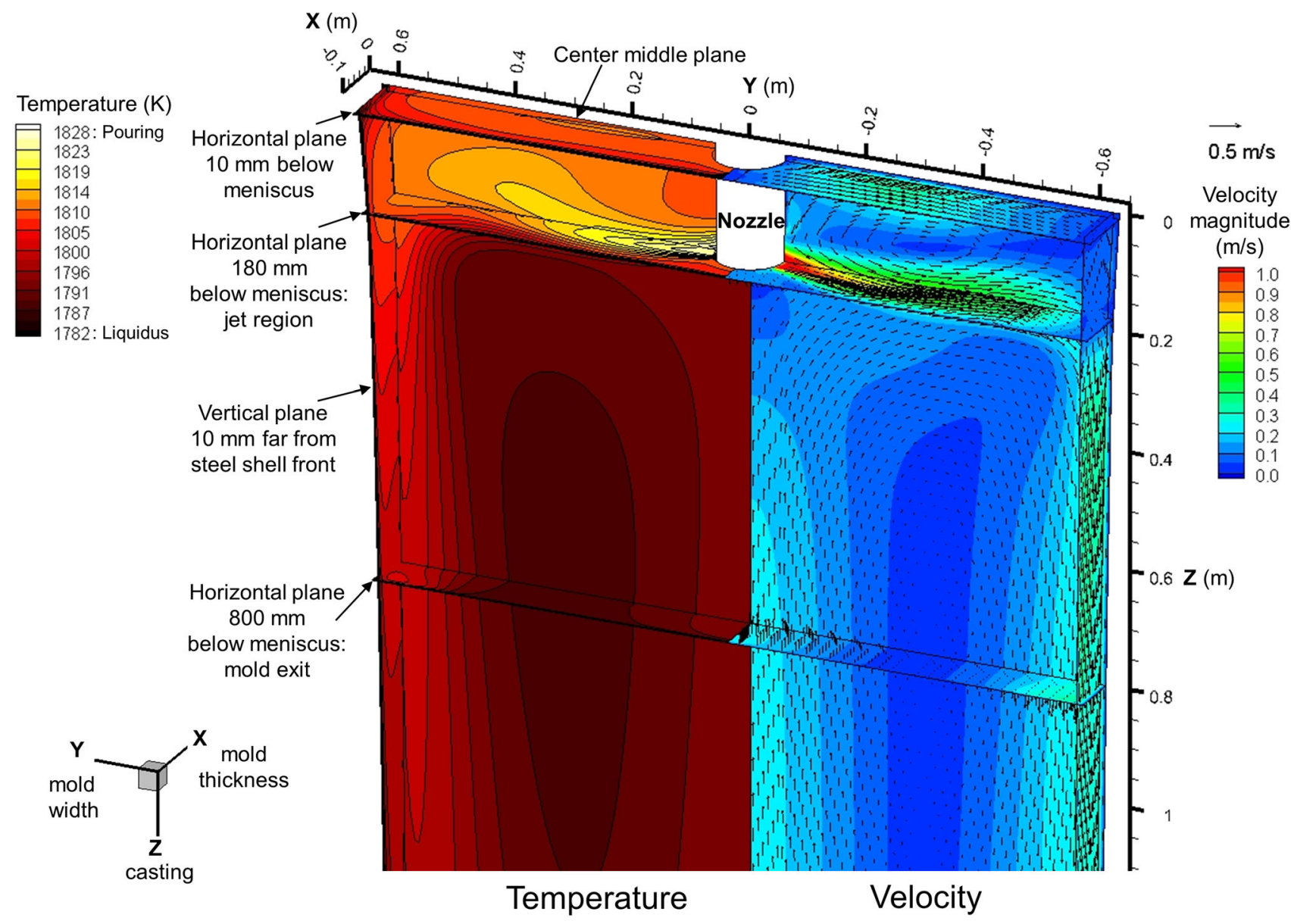

Fig. 1. Molten steel flow with superheat transport in mold regions during continuous steel-slab casting. Reprinted with permission from Ref. 26

particles in the steel, so is relatively unaffected by the steel flow. On the other hand, the capture of large particles at the steel shell front, mechanism 3, is more important to steel quality and is greatly affected by the steel flow. ${ }^{35}$

\section{Deep Oscillation Marks}

Mold oscillation is an essential operation to prevent sticking of the solidifying steel shell to the mold walls during continuous casting. Even with mold oscillation, however, sufficient lubrication between the steel shell and mold is important to prevent quality and operational problems. Mold oscillation forms periodic oscillation marks on the surfaces of as-cast products, as shown in Fig. 5. The oscillation mark shape, including its width, depth, and pitch, depends on the complex phenomena governing initial solidification in the meniscus region, including the meniscus shape, local superheat delivery, heat transport between the molten steel pool and mold wall, meniscus solidification, and initial shell distortion. ${ }^{39-43}$ This is greatly affected by steel grade, ${ }^{39}$ as ultra-low carbon steels and peritectic steels tend to form deeper hooks. ${ }^{39-41}$

Deep oscillation marks are problematic because they lower heat transfer locally across the gap between the steel shell and the mold. The resulting nonuniform heat transfer can produce local thin spots in the shell, higher temperatures, and grain growth, leading to stress concentration and cracks, especially transverse cracks at the roots of the oscillation marks. ${ }^{44-46}$ This problem becomes more severe with unoptimized mold taper. ${ }^{44,46}$ Thus, it is important to properly control oscillation mark formation at the meniscus, which greatly depends on the temperature and fluid flow conditions at the meniscus.

\section{Surface Depressions and Cracks}

Longitudinal surface depressions, which can lead to longitudinal cracks and other problems, initiate near the meniscus in the mold. They are greatly affected by fluid flow, in addition to other issues such as unoptimized mold taper. ${ }^{48,49}$ Level fluctuations and lubrication problems associated with poor control of fluid flow in this region are another cause of nonuniform heat transfer across the steel shell/mold gap, leading to surface depressions. This can further aggravate local hot and thin spots in the initial shell, resulting in local stress concentration, growth of the depressions via necking and buckling, ${ }^{50}$ and cracks, especially longitudinal cracks, which grow as they move down the caster. 

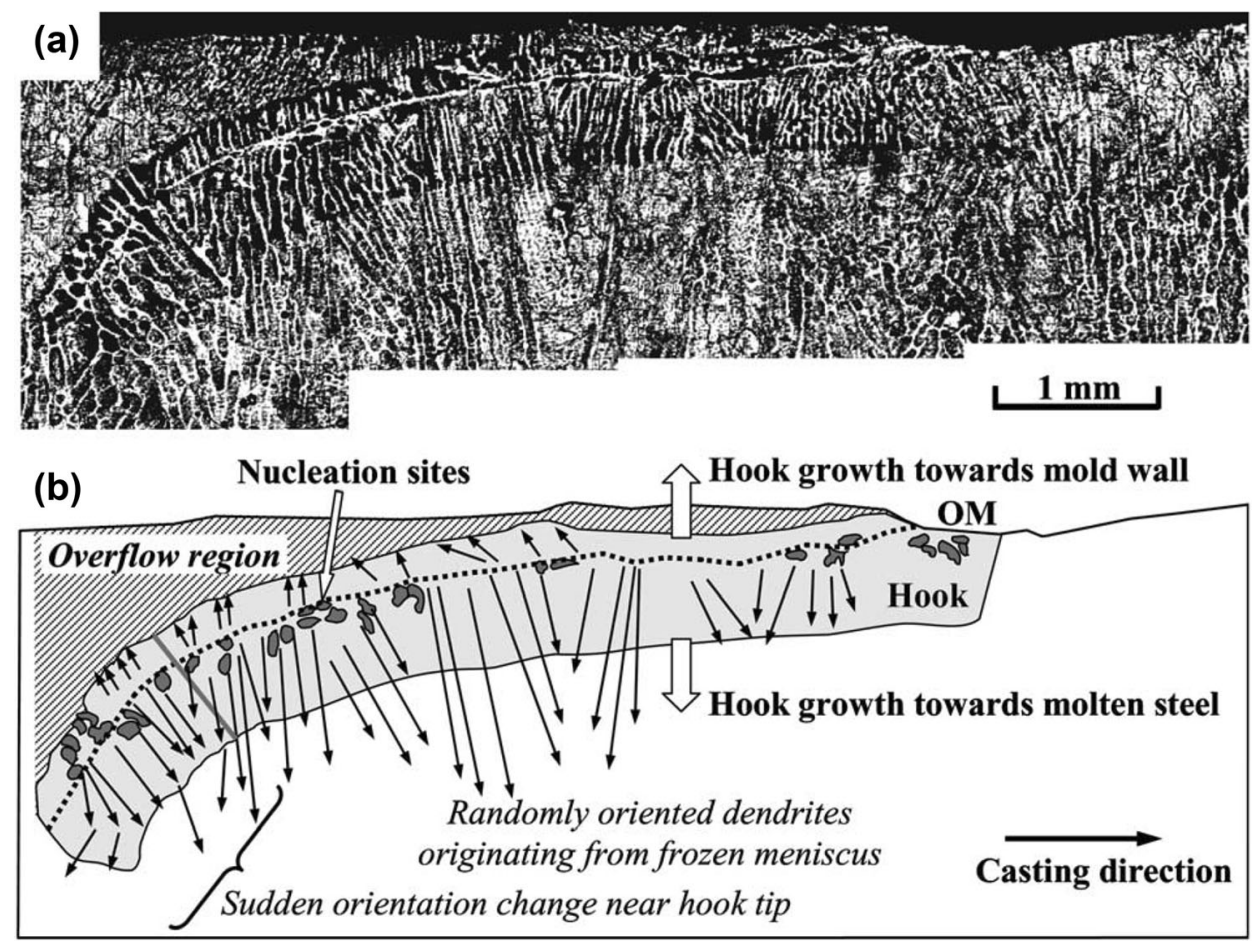

Fig. 2. Subsurface hook formation during continuous steel-slab casting of ultralow carbon steel: (a) measured and (b) schematic. Reprinted with permission from Ref. 22

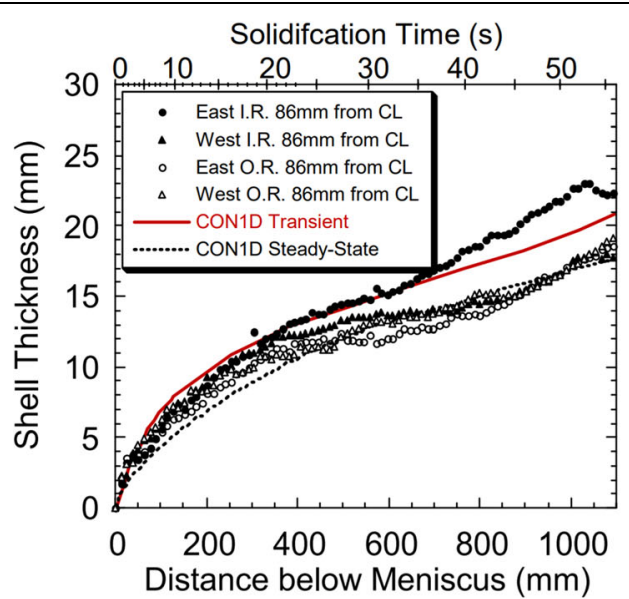

(a)

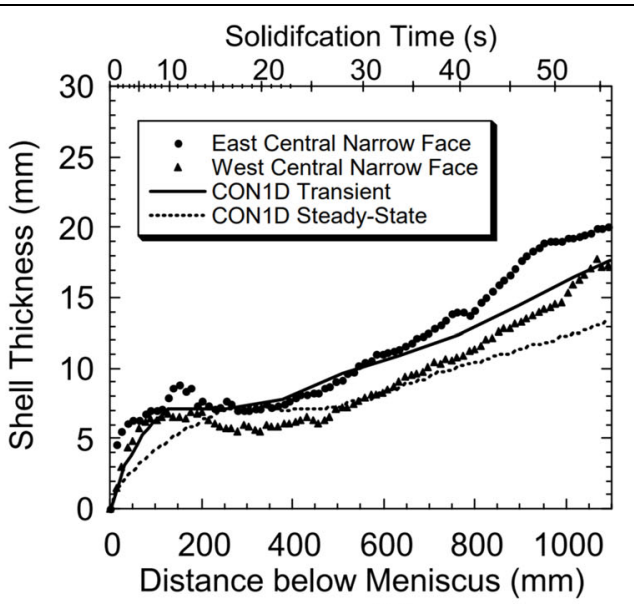

(b)

Fig. 3. Effect of superheat on steel shell profiles and erosion on (a) wide faces and (b) narrow faces. Reprinted with permission from Ref. 27

Longitudinal depressions and cracks can form via several different mechanisms. For example, offcorner longitudinal depressions (gutters) may form in two stages: (1) creation of a hot, thin region on the off-corner of the wide face shell in the mold and (2) cyclic bending of the shell due to bulging between rolls below the mold. ${ }^{48}$ Peritectic steels are particularly prone to this problem, owing to their readily forming depressions due to the extra shrinkage that accompanies the delta to austenite phase transformation. Figure 6 shows the evolving changes in the shape of the solidifying steel shell in the mold region during continuous casting of stainless steel slabs.
Each frame shows the temperature distribution and shape of a horizontal cross-section plane through the solidifying shell near the corner. The off-corner regions of both the wide-face and narrow-face shells are subject to bending, which induces strain concentration leading to cracks at the solidification front. $^{51}$

Depressions can be reduced by controlling the steel flow pattern to avoid severe level fluctuations and to maintain adequate liquid mold flux infiltration around the perimeter of the meniscus. In addition, taper of the narrow-face mold walls should be optimized, adequate spray intensity should be 

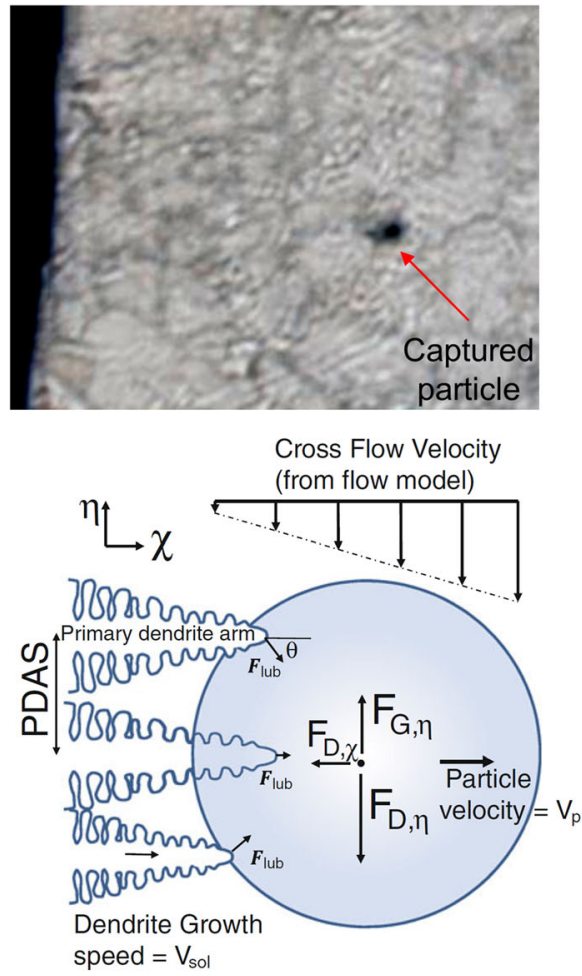

(a)

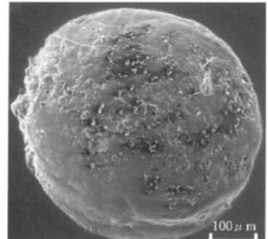

Bubble with inclusions

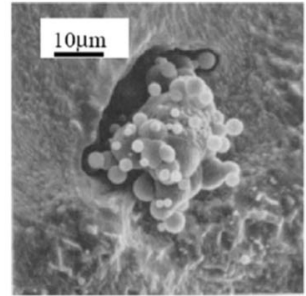

Alumina cluster

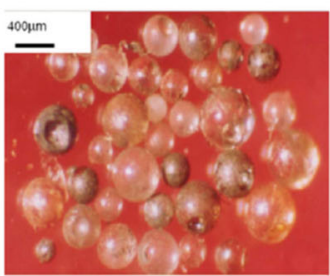

Slag inclusions

(b)

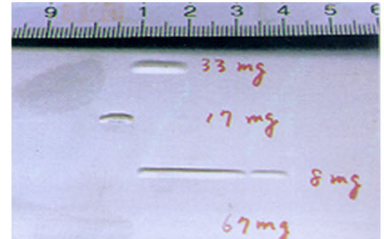

Blister

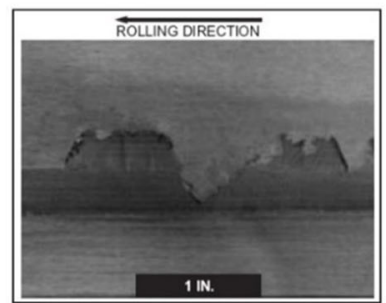

Sliver

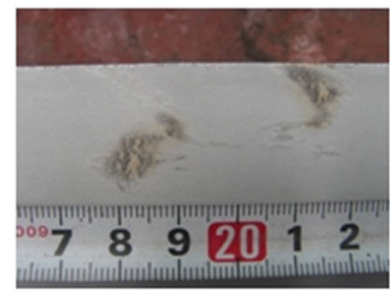

Scab

(c)

Fig. 4. (a) Particle entrapment into the solidifying steel shell. Reprinted with permission from Ref. 33. (b) Captured particles. Reprinted with permission from Refs. 36,37 . (c) Particle capture defects in the final steel products. ${ }^{30,38}$ Reprinted with permission from Ref. 30

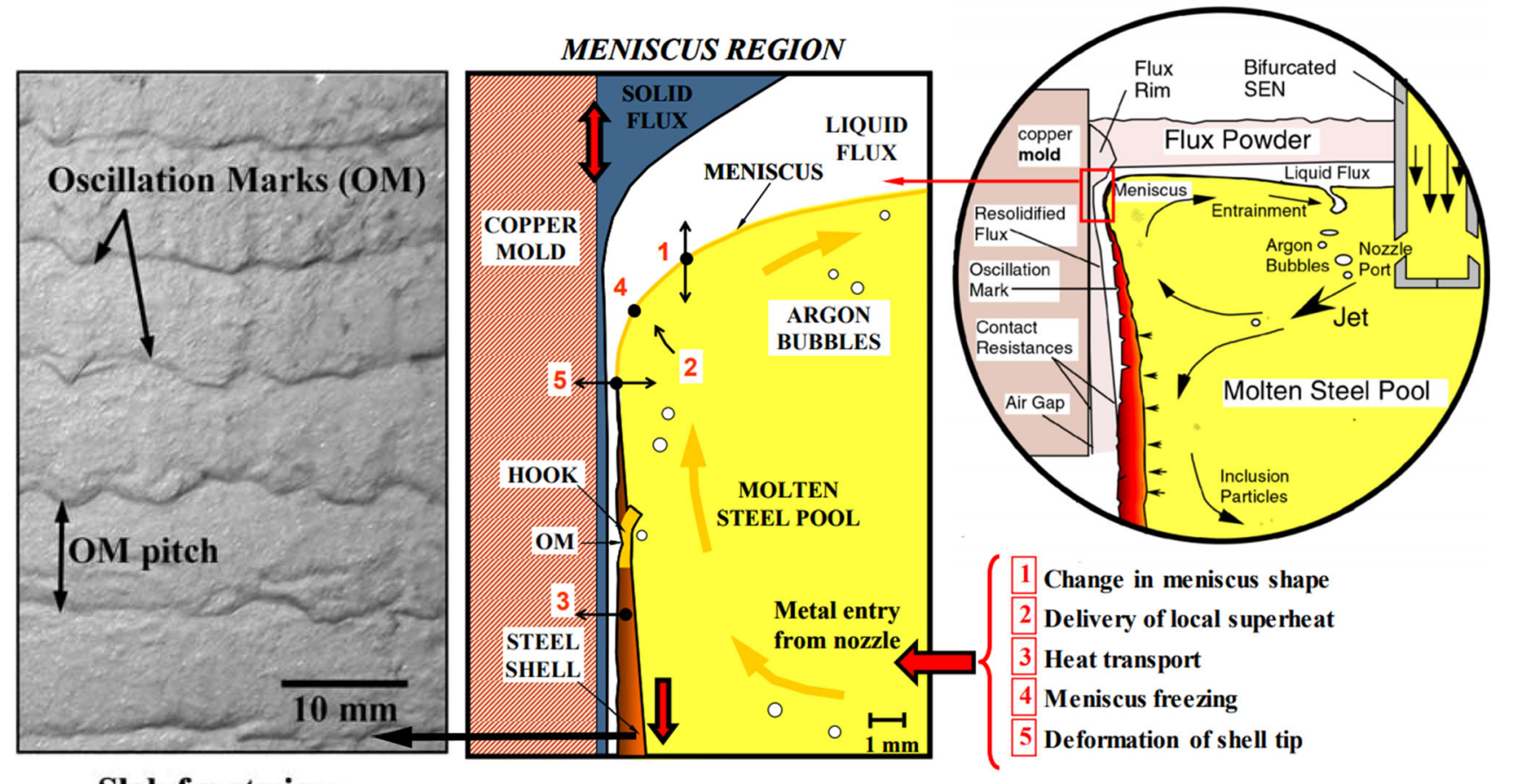

\section{Slab front view}

Fig. 5. Complex phenomena in the meniscus region and oscillation mark formation during continuous steel casting. Reprinted with permission from Refs. 22,47 


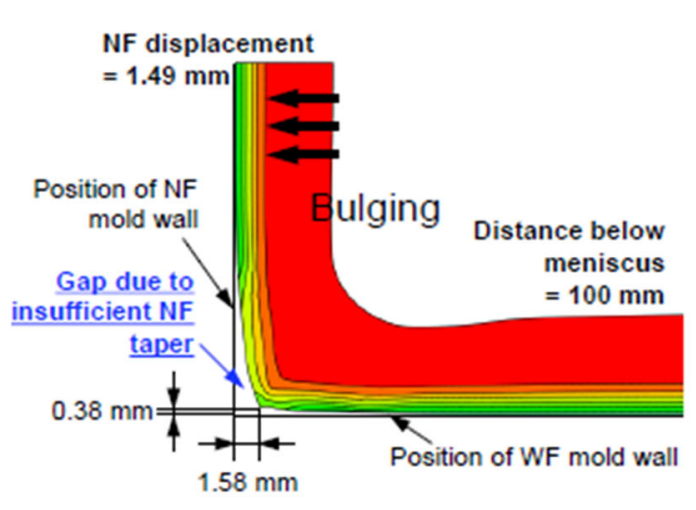

$100 \mathrm{~mm}$ below meniscus

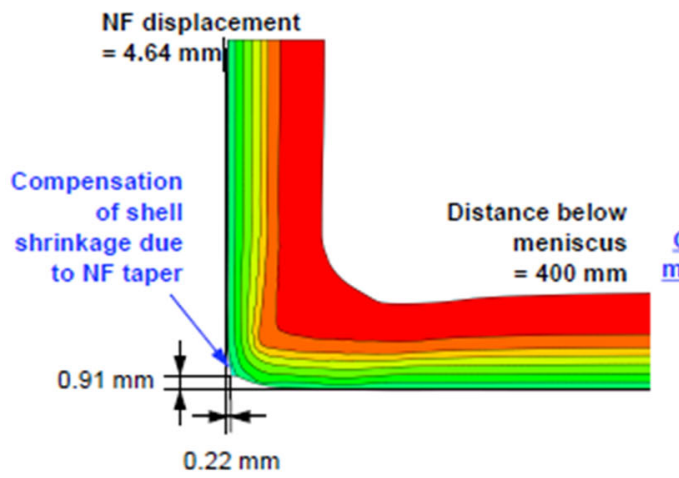

$400 \mathrm{~mm}$ below meniscus

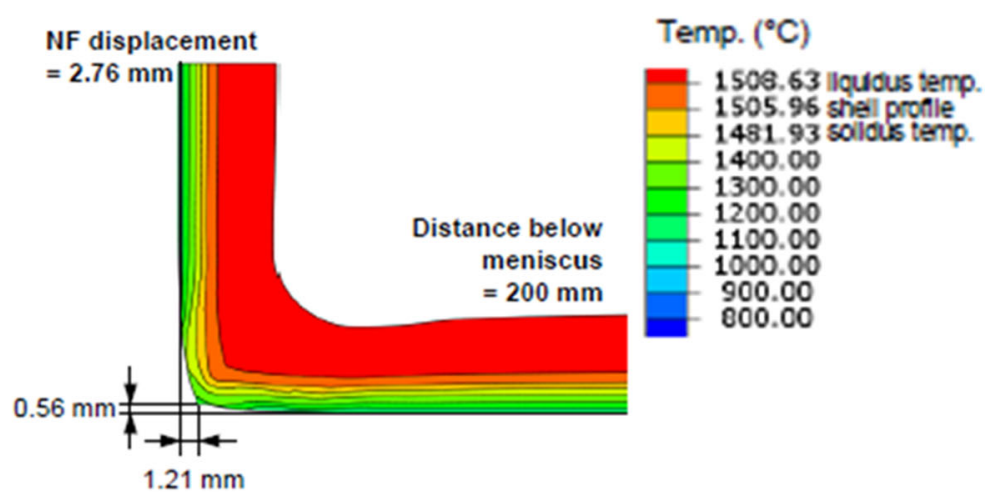

$200 \mathrm{~mm}$ below meniscus

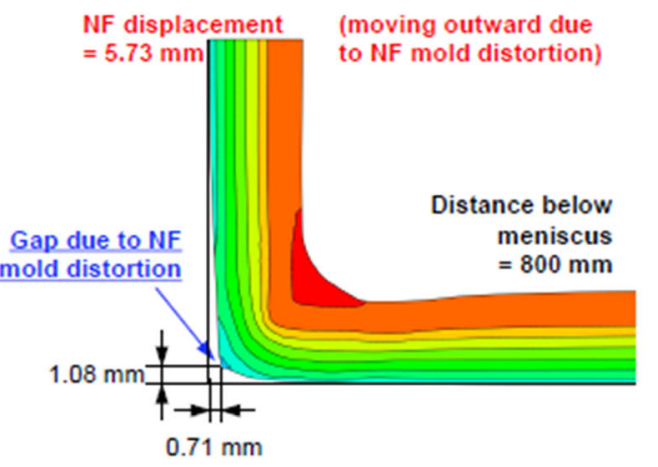

$800 \mathrm{~mm}$ below meniscus

Fig. 6. Depression formation during continuous casting of stainless steel slabs. Reprinted with permission from Ref. 51

maintained uniformly around the shell perimeter below the mold, and roll misalignment and bulging problems should be avoided. ${ }^{48}$

Other types of longitudinal cracks form via different mechanisms. Recent work has shown that some idea of the mechanism can be obtained from the crack appearance, including the shape and location of any associated surface depression. ${ }^{52}$ To gain further insight into the formation mechanism of a particular surface defect, which is an important first step to enable the best corrective action, online sensor data should be monitored and appropriately displayed and analyzed. Such online sensor data include the mold level, mold water heat up, and mold temperature measurements.

Different surface defects have different thermal signatures, which can enable them to be recognized. Impending sticker breakouts, for example, can be recognized by their distinctive inverted mold heat flux profile, which moves down the mold with the thin spot. ${ }^{53}$ Breakout detection systems can recognize the evolving pattern in the temperatures from two or three mold thermocouples and take corrective action, slowing down the casting speed to thicken the shell and avoid the impending breakout. $^{53}$

Recently, high-density temperature measurements have been obtained from fiber Bragg grating sensors ${ }^{9,10}$ embedded in the mold plates. An example of the instantaneous temperature distribution from such a system is given in Fig. 7a, which includes $>200$ measurements every $0.5 \mathrm{~s}^{9,26,52}$ The corresponding image of the strand surface at the same time is given in Fig. 7b. This image shows a longitudinal depression at $\sim-400 \mathrm{~mm}$, which later metallography revealed to contain longitudinal cracks. This longitudinal depression caused mold heat flux to lessen locally, which is manifested by lower local mold temperatures relative to the standard temperature profile. Figure $7 \mathrm{c}$ shows the difference between Fig. $7 \mathrm{a}$ and the standard temperature profile, where the darker colored region near the meniscus provides some evidence of this surface defect. Because this defect evolves by moving down the mold at the casting speed, integration of the data in Fig. 7c according to a new methodology $^{52,54}$ magnifies this difference and is presented in Fig. $7 \mathrm{~d}$. The much darker red region in this frame clearly reveals the longitudinal crack on the slab surface, which is not easy to see in the slab surface photo (Fig. 7b) and is almost impossible to spot in the raw temperatures (Fig. 7a) and intermediate results (Fig. 7c). This new visualization methodology of high-density temperature signals can help to identify defects as they form in real time. In this case, the depression appears to have initiated at the meniscus and moved down the mold, leading to the longitudinal crack. It is likely that this surface defect was initiated by a sudden fluctuation in the top-surface liquid level profile or a local problem 


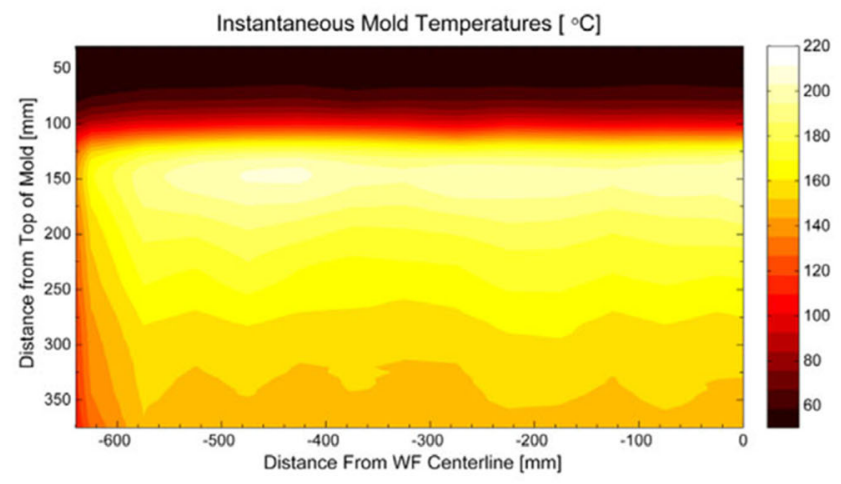

(a)

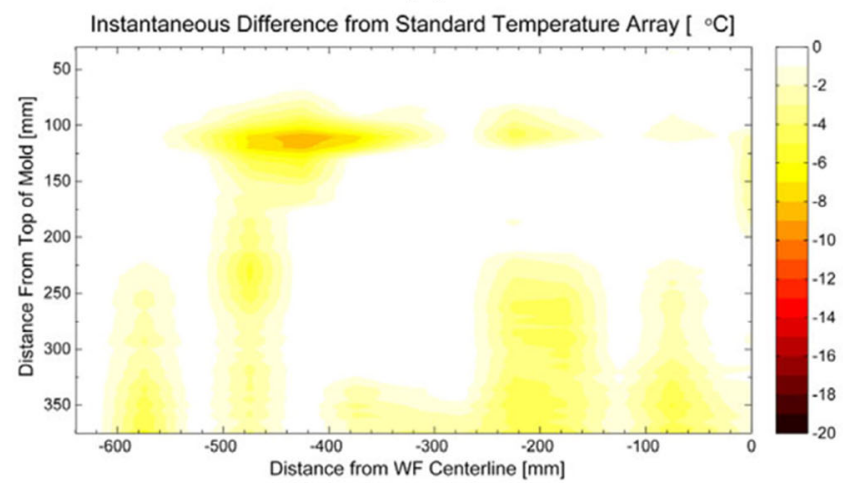

(c)

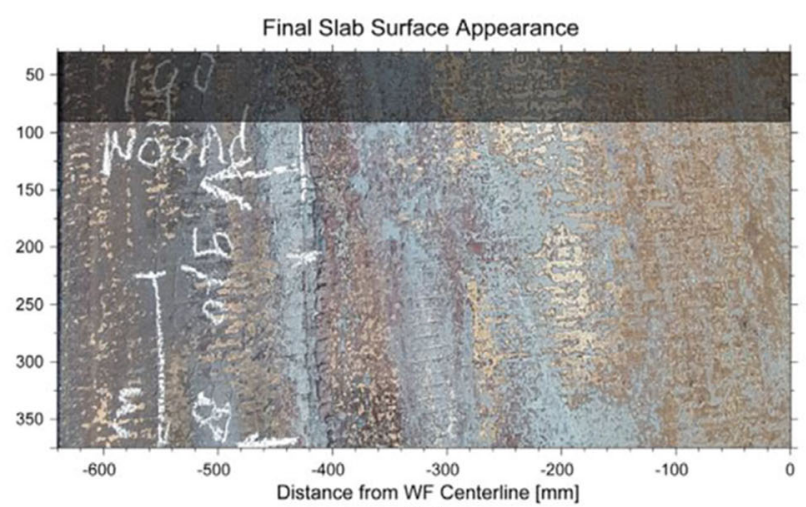

(b)

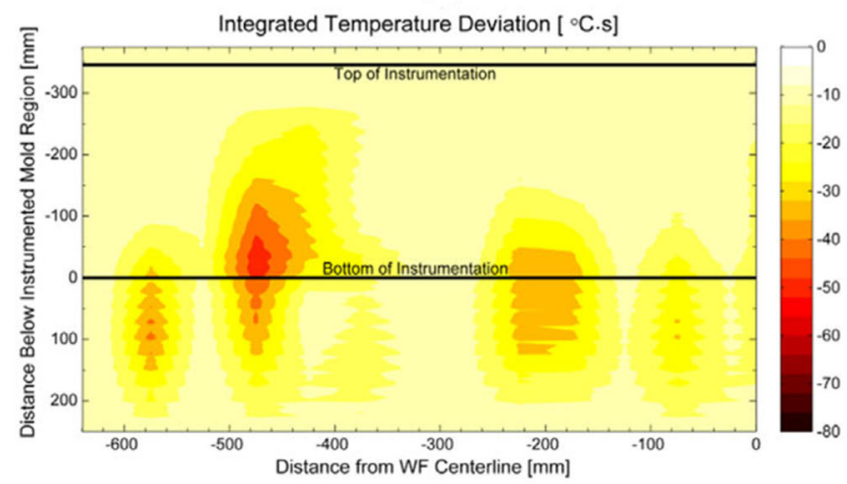

(d)

Fig. 7. Longitudinal crack formation quantified by mapping mold temperature data to slab defect data: (a) instantaneous mold temperature monitored by a fiber Bragg grating system, (b) final slab surface appearance, (c) instantaneous difference from standard temperature, and (d) defect criterion based on integrated temperature drop. Reprinted with permission from Ref. 26

with liquid slag infiltration. Both of these could be associated with problems related to turbulent fluid flow in the mold.

Further implementation of temperature and other sensor data, such as top surface velocity in the mold and mold friction, may be used to extract even more knowledge about scenarios likely to become problematic and to enable corrective action to be taken.

\section{Breakouts}

The most dangerous and costly defect formation in continuous casting is breakout formation. This defect causes safety problems and great expense because production has to be stopped for repairs, in addition to scrapped product. Breakouts mostly initiate from abnormal shell thinning accompanying crack formation, where stress and strain are concentrated to cause hole(s). Through the hole, the molten steel flows out of the steel shell. ${ }^{55-57}$

Figure $8 \mathrm{a}$ and $\mathrm{b}$ shows pictures of a solidified breakout shell and hole that occurred while casting a slab of plain carbon steel. ${ }^{57}$ For this particular breakout, the bottom of the hole where the breakout started appears $\sim 1200 \mathrm{~mm}$ below the top of the solidified breakout shell. This hole became bigger and wider as the shell moved downward during the breakout, while the mold level dropped below the top of the shell. With the aid of a computational model, CON1D ${ }^{24}$ further analysis can reveal further insights and details related to the time histories that led to this breakout, including the evolving size of the breakout hole and the solidification time. In this case, the breakout actually started just at the mold exit, about $800 \mathrm{~mm}$ below the meniscus, and continued to move downward while the casting speed decreased, while the hole opened larger. This is indicated by the location and size of the yellow triangle in the diagram of time and position in Fig. 8c. The shell thickness profiles down the mold at various times show that the changing casting conditions cause the shell growth profile during steady casting, ts, to differ from the final shell thickness profile, even far away from the breakout, ts0. The shell growth profile above the breakout, ts1, is abnormally thin, owing to a local decrease in heat transfer, likely caused by a transient event at the meniscus. This eventually led to the breakout at mold exit, when that growing thin region was no longer supported by the mold.

Preventing breakouts requires casting conditions that can avoid the initiation of local shell thinning and depression formation that leads to crack formation that causes the breakout. ${ }^{55}$ Perhaps this breakout could have been prevented if online 


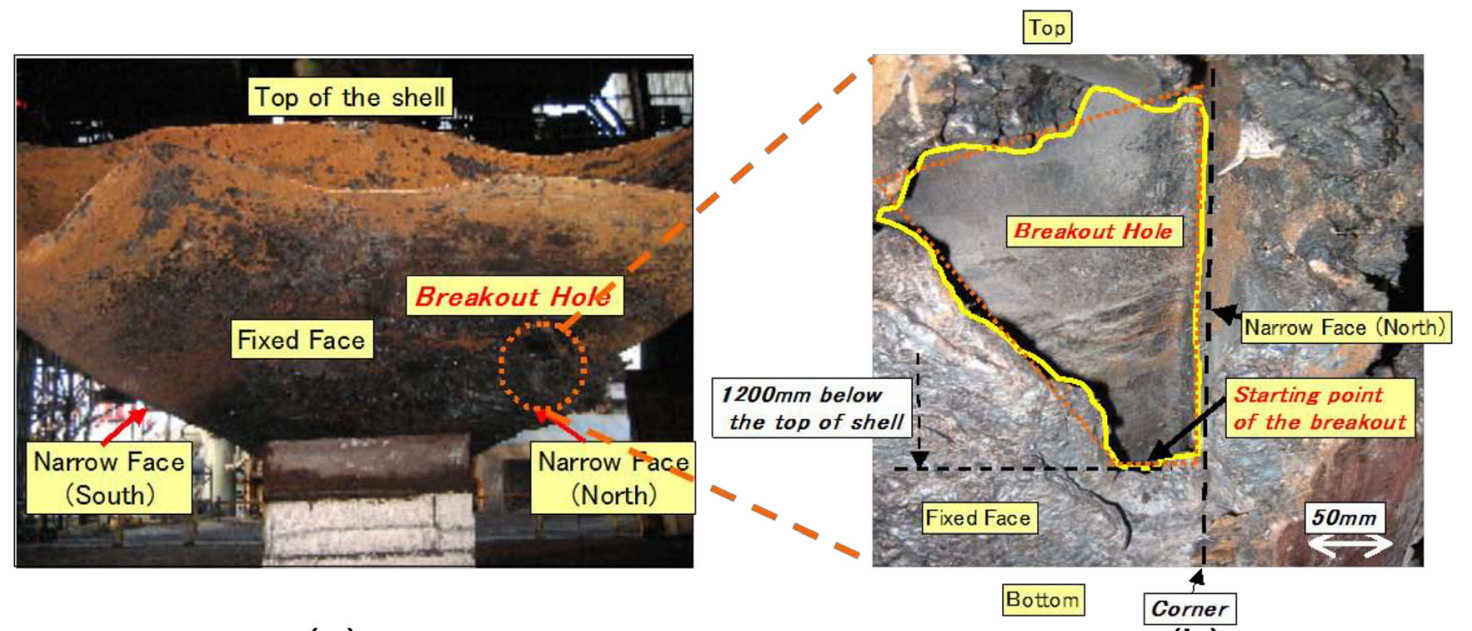

(a)

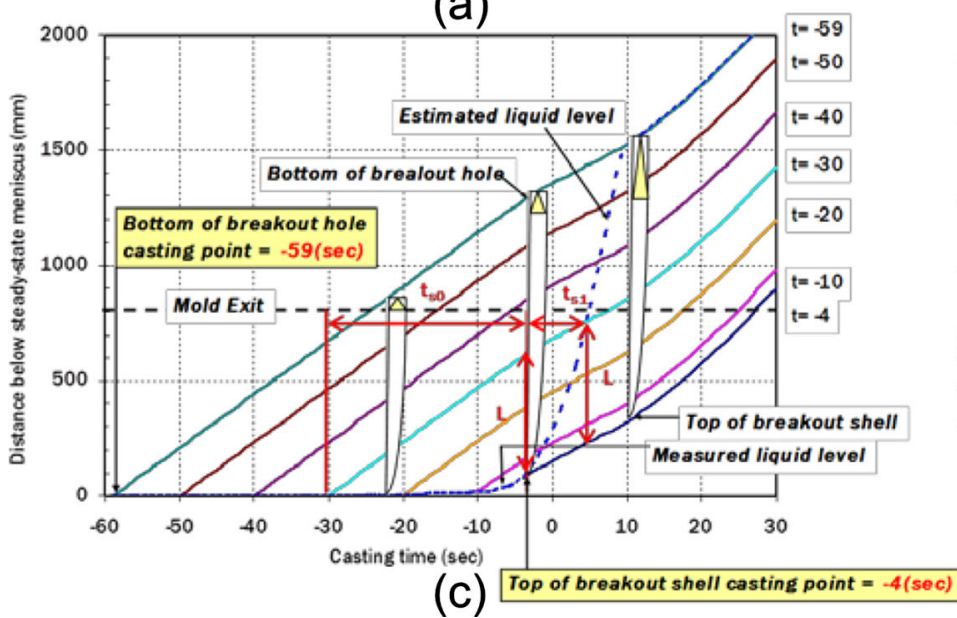

(b)

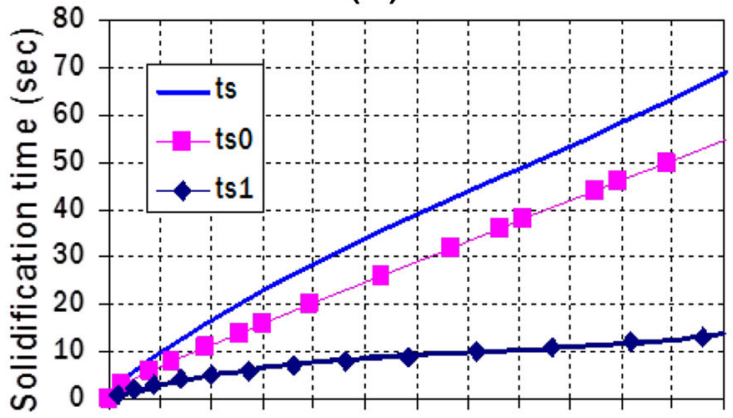

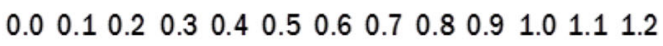
Distance below the top of shell $(\mathrm{m})$

(d)

Fig. 8. Breakout shell showing view (a) looking down and (b) closeup of hole, (c) distance traveled by different points on the shell surface relative to the dropping liquid level, and (d) comparison of solidification times between steady casting and the breakout. Reprinted with permission from Ref. 57

sensors had been implemented and corrective measures were taken quickly after identifying the thin region. Even better would be to control fluid flow in the mold to prevent the initiation of the defect at the meniscus.

\section{Segregation}

The solidified microstructure of continuous-cast steel is generally not homogeneous and includes composition variations known as segregation. Segregation is classified as microsegregation $(<1000 \mu \mathrm{m})$ that arises between the dendrites ${ }^{58}$ or macrosegregation $(\mathrm{mm})$, which involves large distances. Macrosegregation can manifest as centerline segregation due to the high-solute melt moving toward the interior of as-cast steel products ${ }^{59,60}$ or internal hot tears, where interdendritic liquid is drawn in from surrounding regions to form segregation in the shape of a crack. Segregation is often accompanied by nonuniform grain structures, porosity, shrinkage cavities, and other microstructural variations. Some of these problems can be removed during subsequent processes, such as rolling, which can close up internal voids, or homogenization heat treatment, which can remove microsegregation by diffusion. Macrosegregation, however, is a serious defect because it can lead to other phases detrimental to the mechanical properties of the final steel product, and it is impossible to remove during later processing.

Macrosegregation originates from molten steel flow due to forced, natural, and solutal convection. If there were no fluid flow, then only microsegregation could arise. The fluid flow transports solute elements or grains over large distances. Internal solid phases may arise from remelting of dendrite tips or heterogeneous nucleation of equiaxed grains in regions of solutal undercooling. Thus, it is important to carefully control the fluid flow with the aid of nozzle design and/or electromagnetic fields.

Figure 9a shows the internal grain structure in a billet sample that contains macrosegregation and other defects. In this example, bridging of low-alloy grains appears to have connected the two solidification fronts and prevented liquid feeding into the region below, resulting in both centerline and V- 


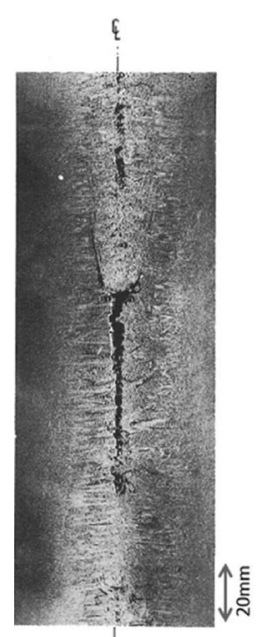

(a)

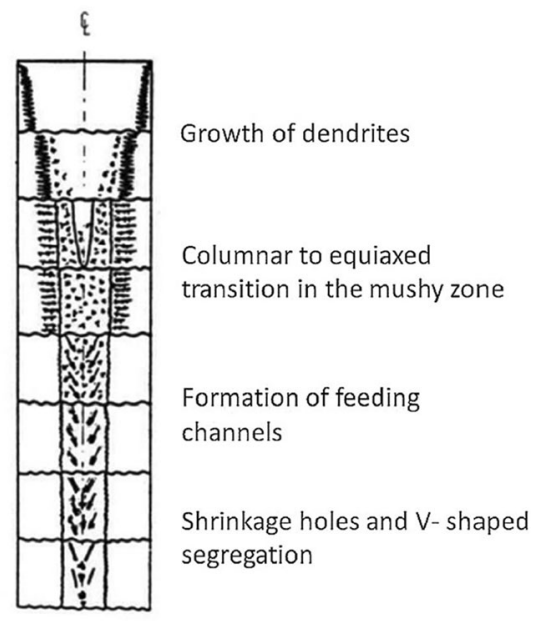

(b)
Fig. 9. (a) As-cast structure of a billet with V-shaped segregation and shrinkage and (b) schematic of the formation of the internal solidification defects during the solidification of billets. Reprinted with permission from Ref. 59

shaped macrosegregation due to the subsequent shrinkage. A schematic of the $\mathrm{V}$ segregation and shrinkage defects is given in Fig. 9b. In slab casting, centerline segregation is likely formed due to nonuniformities in the mainly one directional heat extraction towards the wide faces during the final stages of solidification near the metallurgical length of the caster. ${ }^{59}$

\section{ELECTROMAGNETIC EFFECTS}

Electromagnetic fields can be applied to the mold, submold, or final solidification regions of the solidifying steel strand to directly alter the fluid flow field of electrical-conducting molten steel. Static fields such as local electromagnetic braking $(\mathrm{EMBr}){ }^{61}$ single-ruler $\mathrm{EMBr},{ }^{62}$ or double-ruler $\mathrm{EMBr}^{61,63,64}$ are designed to generate a region of high flow resistance to deflect the molten steel jets in the mold and to control the mold flow pattern. The usual objective is a stable double-roll flow pattern, where the molten steel first impacts on the solidifying steel shell against the narrow faces and deflects upwards and downwards to create four recirculation regions, ${ }^{65}$ such as shown in Fig. 1. Alternatively, moving fields such as the electromagnetic level stabilizer (EMLS) ${ }^{65,66}$ electromagnetic level accelerator (EMLA), ${ }^{65,66}$ or electromagnetic rotating stirrer (EMRS) ${ }^{66,67} / \mathrm{mold}$ electromagnetic stirring (M-EMS) ${ }^{68,69}$ are designed to slow down, speed up, or rotate the mold flow by adjusting the frequency of the phase-shifted alternating current in different magnets positioned along the mold wide faces. Recently, combined fields have been developed to apply a moving field to stir the flow in the upper mold and a braking field to deflect the flow in the lower mold. ${ }^{70}$ In the strand region, Strand EMS is often used to purposely produce vertically rotating flow recirculation in slab casting or horizontally rotating flow around the perimeter of the strand wall in bloom or billet casting. ${ }^{67,71,72}$ Final EMS is applied to generate strong horizontal rotating flow in the final solidification zone near the metallurgical length of the caster, which is popular in billet casting of high-carbon and alloy steel grades. ${ }^{67,71}$ Further details of these different electromagnetic systems are discussed in a recent review paper. ${ }^{18}$ In addition to the different system configurations, the locations and numbers of magnets, the applied current to control the field strength, and the different frequencies and phase shifts of moving fields together present a huge number of parameters to optimize in order to tailor the fluid flow for a given nozzle geometry, set of casting conditions, and operational scenarios. ${ }^{18}$

Due to the important effect of electromagnetic forces on the fluid flow, electromagnetics has a strong indirect effect on many other phenomena related to solidification during continuous casting. These include superheat transport and initial solidification, particle transport and capture, surface quality, grain structure and internal quality, and steel composition distribution. This section reviews the current understanding of how electromagnetic fields can control these solidification-related phenomena and how the associated defects potentially can be reduced by an optimized electromagnetic flow control system.

\section{Control Superheat Transport and Initial Solidification}

Superheat transport by the molten steel flow is important for initial solidification in continuous steel casting, as discussed previously. Superheat is carried with the molten steel flow into the molten steel pool in the mold region and dissipates as the steel flow circulates. ${ }^{73,74}$ Upon reaching the meniscus region, $<\sim 5 \%$ of the superheat remains, depending on the flow pattern. ${ }^{73}$ In some cases, it is likely that the molten steel at the meniscus may even become undercooled below its equilibrium solidification temperature ${ }^{75}$ especially in ultralow carbon steels where nucleation is more difficult. The flow pattern in the mold controls the intensity of surface flow, which controls intermixing and melting of the mold slag as well as superheat transport to the meniscus region. Generally, more superheat is delivered to the meniscus if the jets of molten steel are directed upwards. On the other hand, deflecting the jet downward dissipates the superheat deep in the strand, resulting in less superheat transport to the top surface. In particular, lowervelocity, almost stagnant flow is often found at the meniscus near the SEN and corner regions, which tend to make them the coldest regions, which can 
lead to deep hooks and oscillation marks, slag infiltration problems, poor lubrication of the steel shell/mold gap, and associated problems of crack formation.

EMBr magnetic fields, including local, singleruler, and double-ruler $\mathrm{EMBr}$, can be adjusted to deflect the jet upwards or downwards and thereby control both the intensity of surface directed flow and the transport of superheat to the meniscus region. This has a critical effect on initial solidification and surface defects.

With local or single-ruler EMBr systems, the location of the field related to the jet from nozzle ports is critical to change the flow pattern in the mold, leading to different surface flow intensity and superheat transport behavior. When the local EMBr field is located below the jet, it deflects the jet slightly upward, towards the top surface, which promotes faster surface flow and more superheat delivery toward the meniscus. ${ }^{76}$ As shown in Fig. 10, this results in higher meniscus temperature and enhanced slag mixing and infiltration near the meniscus leading to less hook formation and improving initial solidification, so long as the flow is not so intense and turbulent that it causes level fluctuations and chaotic meniscus solidification. In addition, this meniscus heating effect increases with higher field strength, as shown in Fig. 10. On the other hand, locating the local EMBr field above the jet deflects the jet downward in the mold and carries less superheat to the surface slag layer, leading to lower surface flows. ${ }^{77-79}$ As previously mentioned, insufficient surface flow leads to meniscus freezing, deeper hooks, infiltration problems, and surface defects. Thus, ordinary variations in submergence depth can greatly affect the consequence of the local EMBr field. These findings show how very important it is to monitor the relative positions of the jet and the $\mathrm{EMBr}$ field, according to the combined interactions of all of the casting conditions, in order to control superheat transport and initial solidification.

Double-ruler $\mathrm{EMBr}$, locating two static fields across the mold width, located above and below the nozzle ports, is designed to stabilize the mold flow, surface velocity, and meniscus temperature. Transient variations due to turbulence that send the jet downward create stronger Lorentz forces to deflect it back into the desired steady position, while chaotic upward variations are deflected back down. Thus, this static field can be naturally self-stabilizing if designed properly. ${ }^{63,64}$

Controlling the strengths of the upper and lower rulers is important to control the natural steady position of the jets. A stronger upper-ruler field results in a stable jet that is directed more

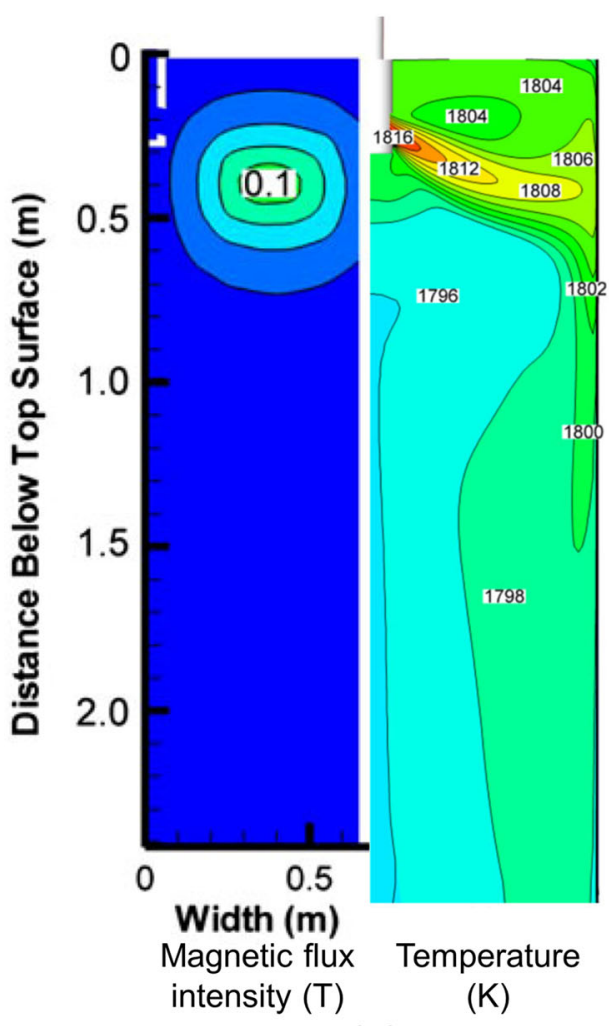

(a)
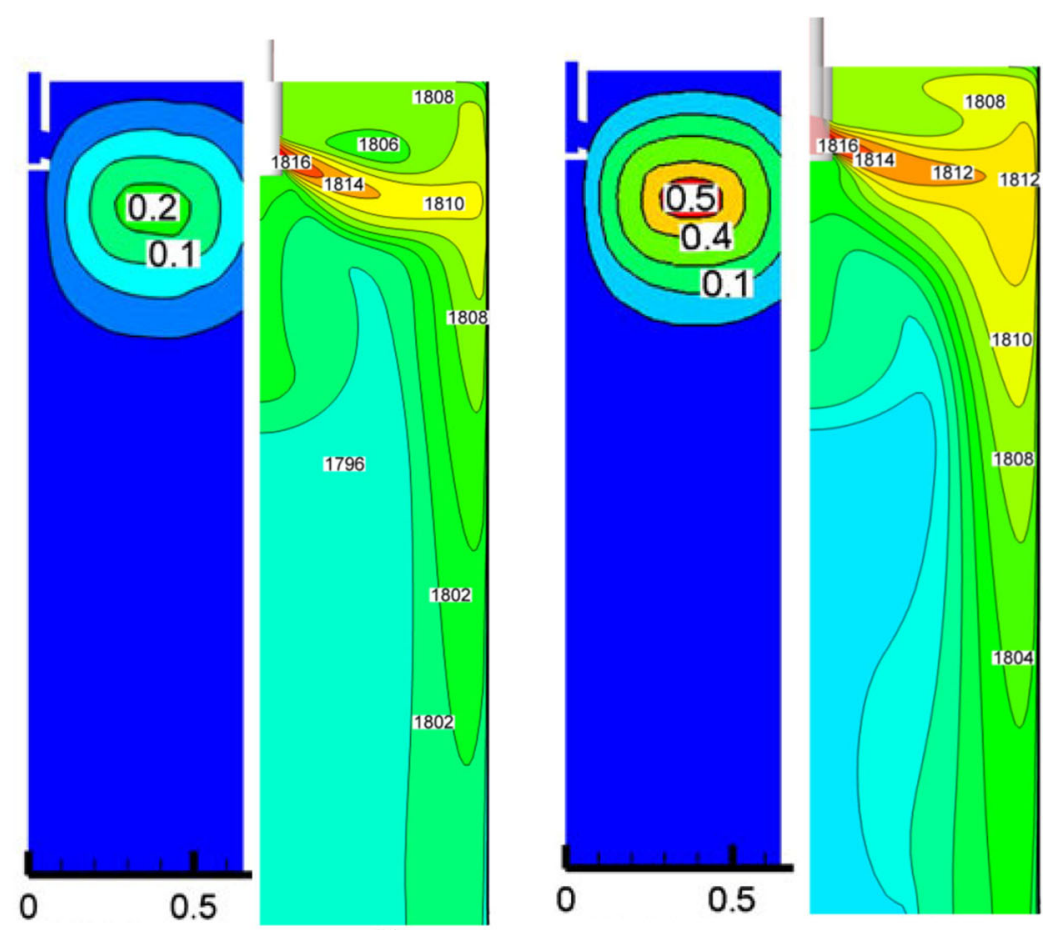

(b) (c)

Fig. 10. Effect of local EMBr on temperature distribution in the mold: local EMBr field strength $\mathrm{B}_{0}$ of (a) 0.0 T, (b) $0.2 \mathrm{~T}$, and (c) $0.39 \mathrm{~T}$. Reprinted with permission from Ref. 76 
downward, sending less flow and less superheat to the meniscus. Alternatively, a stronger lower-ruler field tends to stabilize the jet with a shallower angle when it impinges on the narrow face, resulting in stronger surface flows and more superheat carried to the meniscus. The choice depends on how all of the other casting conditions combine. If the upward jet toward the top surface is too strong, excessive surface velocities and severe surface level fluctuations can arise. Figure 11 shows the effects of double-ruler $\mathrm{EMBr}$ with a stronger lower field on superheat transport, hook depth, and inclusion capture in a typical slab caster. Directing more flow and superheat towards the top surface increases the temperature near the meniscus. This produces shallower hook depth and thus less capture of particles. ${ }^{80}$ Thus, proper adjustment of the doubleruler $\mathrm{EMBr}$ field strengths is essential to maintain the quality of as-cast slabs.

Horizontally moving fields in the mold, such as EMRS/M-EMS, EMLS, or EMLA, have different effects on superheat transport and initial solidification according to the flow problem that the electromagnetic system is trying to solve.

EMRS or M-EMS generates horizontal rotating flows around the steel shell front, designed to promote better mixing of the molten steel pool. This tends to increase surface flow velocity and superheat transport and tends to make temperature distribution around the mold perimeter more uniform. ${ }^{6,81}$ This results in more uniform initial solidification. In addition, more superheat is delivered to the meniscus corner regions, which reduces hook depth and particle capture. Furthermore, this also improves uniformity of the fluid flow and liquid slag layer thickness near the meniscus, leading to more uniform slag infiltration into the gap between the steel shell and mold. This can increase the uniformity of heat transfer and shell growth around the perimeter, perhaps leading to fewer defects such as longitudinal cracks.

EMLA is designed to increase the jet velocity, resulting in higher surface velocity, ${ }^{65,82}$ which would help to alleviate problems of slow or stagnant surface flow conditions, when casting in wide molds at low casting speed, for example. This could reduce problems with meniscus freezing and deep hook formation. ${ }^{65}$ This has similar benefits to local or single-ruler EMBr fields below the jet or double ruler EMBr fields with a stronger lower field.

EMLS is designed to decrease the jet velocity, resulting in lower surface velocities, which aims to
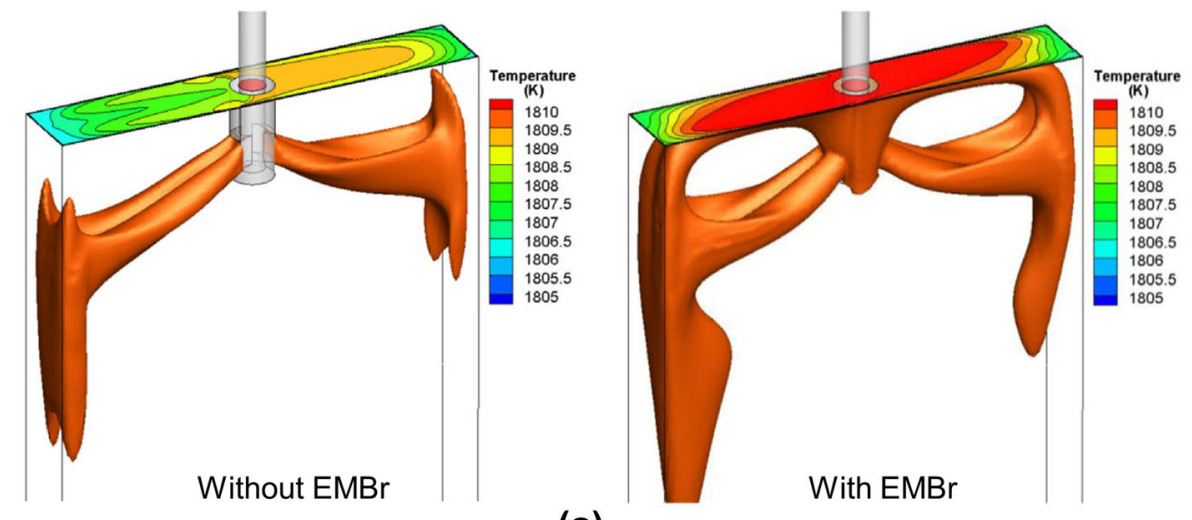

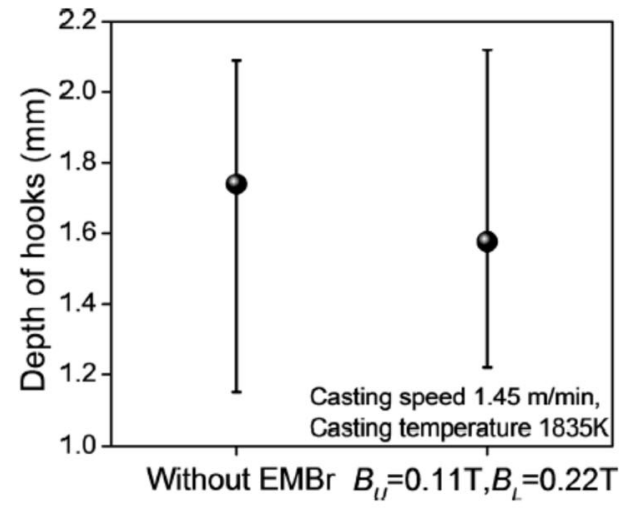

(b) (a)

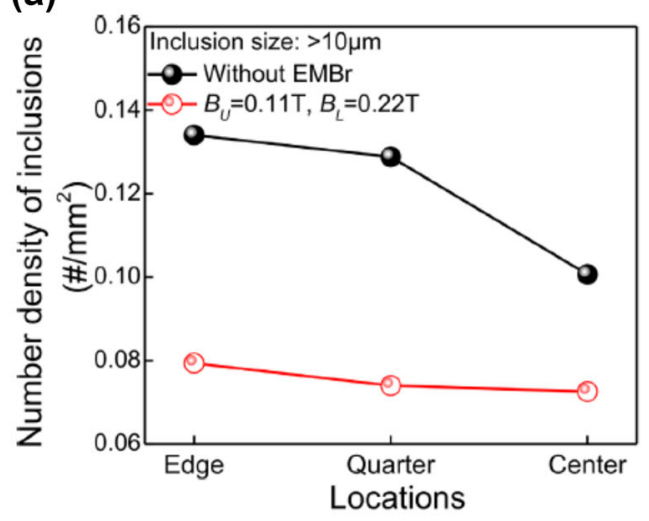

(c)

Fig. 11. Effects of double-ruler EMBr on (a) temperature distribution in the casting mold, (b) hook depth, and (c) inclusion capture in the steel slab. Reprinted with permission from Ref. 80 
prevent excessive surface level fluctuations, ${ }^{66,83,84}$ which are detrimental to initial solidification at the meniscus, as previously discussed. This system is most likely to be useful when casting in narrow molds at high casting speed. This system has similar effects to local or single-ruler EMBr fields located above the jet or double ruler EMBr with a stronger upper field. In every case, it is important to identify whether the surface flow and temperature should be increased or decreased before it is possible to optimize the electromagnetic flow control system.

\section{Lessen Particle Capture Defects}

The application of EMBr fields to deliver more superheat to the meniscus to improve initial solidification has the important consequence of lessening particle capture defects by decreasing deep hooks, as shown in Fig. 11c. ${ }^{80}$ Stronger flow along the top surface in the mold also lessens the chance of stagnation at the meniscus, again lessening the capture of large particles. The application of a strong static magnetic field via an $\mathrm{EMBr}$ ruler located below the jet region can reduce internal inclusion capture by transporting fewer particles deep into the strand region. ${ }^{85}$ However, making the magnetic field below the jet too strong, so that the surface velocity is excessive ( $>0.4$ or $0.5 \mathrm{~m} / \mathrm{s}^{86-88}$ ), can increase slag entrainment and level fluctuations, leading to more slag inclusion capture defects. ${ }^{89}$ It is important not to locate the maximum of the magnetic field directly across the nozzle ports, because this creates flow instability and complex flow, again resulting in more slag entrainment and inclusion capture. ${ }^{89}$

The application of EMRS (M-EMS) produces rotating flow in the upper mold, which creates a washing effect on particles near the steel shell front, thereby lessening the chance of large particle capture into the solidifying steel shell. ${ }^{66}$ Care should be taken to avoid excessive stirring, however, to avoid level fluctuations, chaotic turbulent flow, and accompanying defects during initial solidification. Finally, the combined field system has the potential to achieve both effects together by employing a stirring field around the meniscus region (upper field) and a static braking field below the nozzle (lower field). ${ }^{90}$ Thus, once optimized, this new system may be able to decrease both surface and internal defects caused by the particle capture.

\section{Improve Surface Quality}

The upper EMBr ruler, which acts across the nozzle, can stabilize swirl in the nozzle, which lessens jet wobbling at the port exits. Together with its action across the upper mold region, this results in more stable flow in the mold, fewer surface velocity variations, and fewer severe level fluctuations. ${ }^{63}$ This is due to its nature in which the local Lorentz force is proportional to the local velocity, which continuously adjusts to turbulent flow variations, especially on smaller length scales. The stabilized surface flow and decreased level fluctuations can decrease overflow during initial solidification, resulting in more uniform and shallower oscillation mark profiles and fewer surface defects.

Electromagnetic casting (EMC) is a different electromagnetic system ${ }^{91}$ that induces Lorentz forces in the direction perpendicular from the mold wall toward the molten steel pool. This is designed to produce soft contact between the steel shell and the mold wall near the meniscus and make the oscillation mark depth shallower, as shown in Fig. 12. These forces tend to create two recirculation flows of molten steel near the meniscus, which likely increases local superheat delivery to the meniscus, decreases overflow during initial solidification and creates less pressure during the negative strip part of the mold oscillation cycle. The optimized application of EMC is revealed to remarkably increase surface quality with much shallower oscillation marks and hooks. ${ }^{91}$

\section{Gain More Equiaxed Grains and Less Segregation}

The grain structures produced in continuous casting include the chill, columnar, and equiaxed zones extending from the surface to the center of the cast product. In addition to the steel composition, the relative size of these zones strongly depends on heat transfer and flow behavior inside the mold and strand region. The grain structure is important for internal quality and mechanical properties. More equiaxed grains tend to decrease segregation and porosity defects and improve mechanical properties such as strength and ductility. ${ }^{92}$

M-EMS generates a horizontal rotating electromagnetic field around the perimeter of the mold walls near the meniscus. This can increase nuclei formation by decreasing the heat transfer gradient and/or melting dendrite tips by increasing the molten steel velocity across the solidification front and by removing more superheat in the mold so that the nuclei can survive and grow as they are transported deep into the caster. ${ }^{68,93}$ This is expected to lead to a larger fraction of equiaxed grains in the as-cast steel product.

Strand electromagnetic stirring (SEMS) systems induce an electromagnetic field towards one narrow face, which produces vertical recirculating flows in slab casting. Alternatively, S-EMS can produce a horizontal rotating field around the steel shell front, generating a similar flow pattern with M-EMS deep into the strand for bloom and billet casting. Figure 13 shows the effects of SEMS on the flow pattern and grain structure in slab casting. Mixing the flow in the strand region decreases temperature gradients in the molten steel pool and helps to increase the fraction of equiaxed grains. ${ }^{67,71,94-96}$ In addition, SEMS employed together with a heavy soft-reduction process, such as developed at Posco, ${ }^{7}$ 


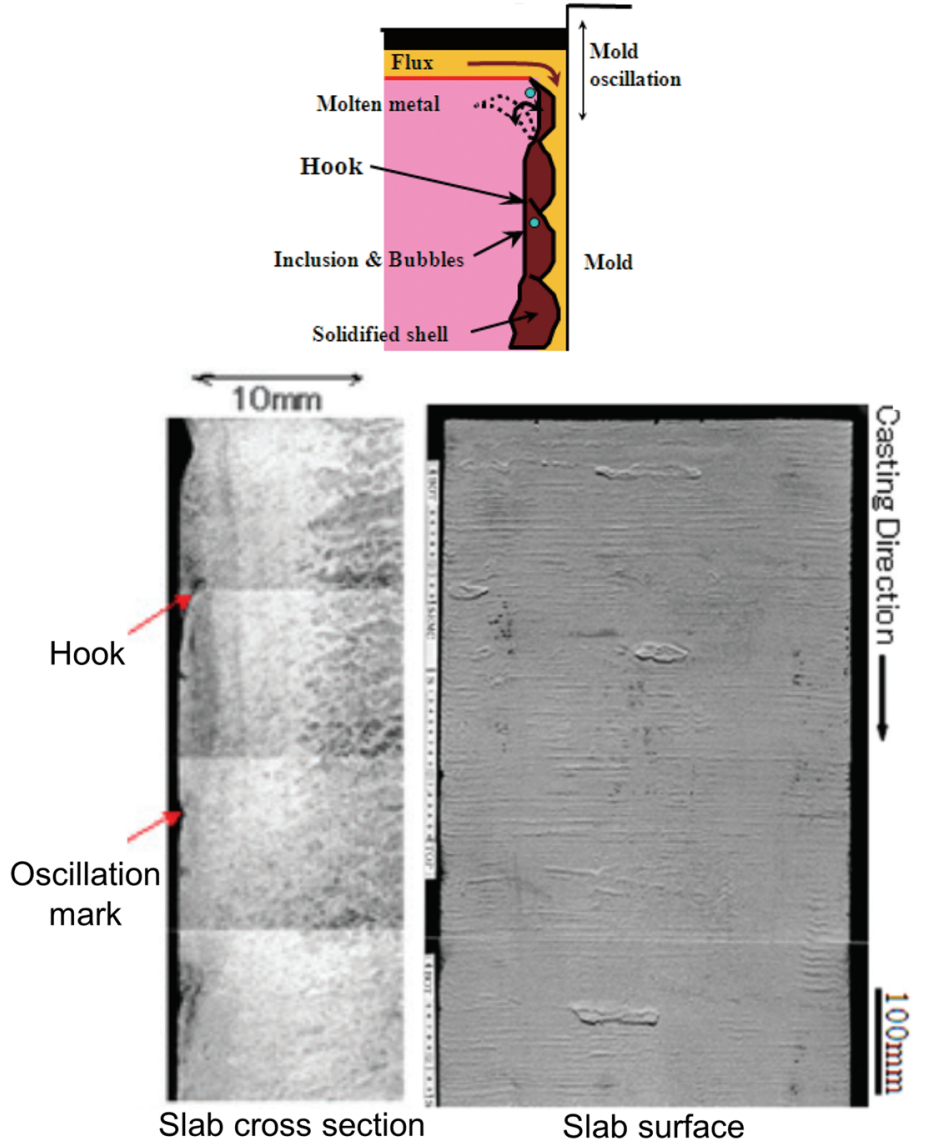

(a)

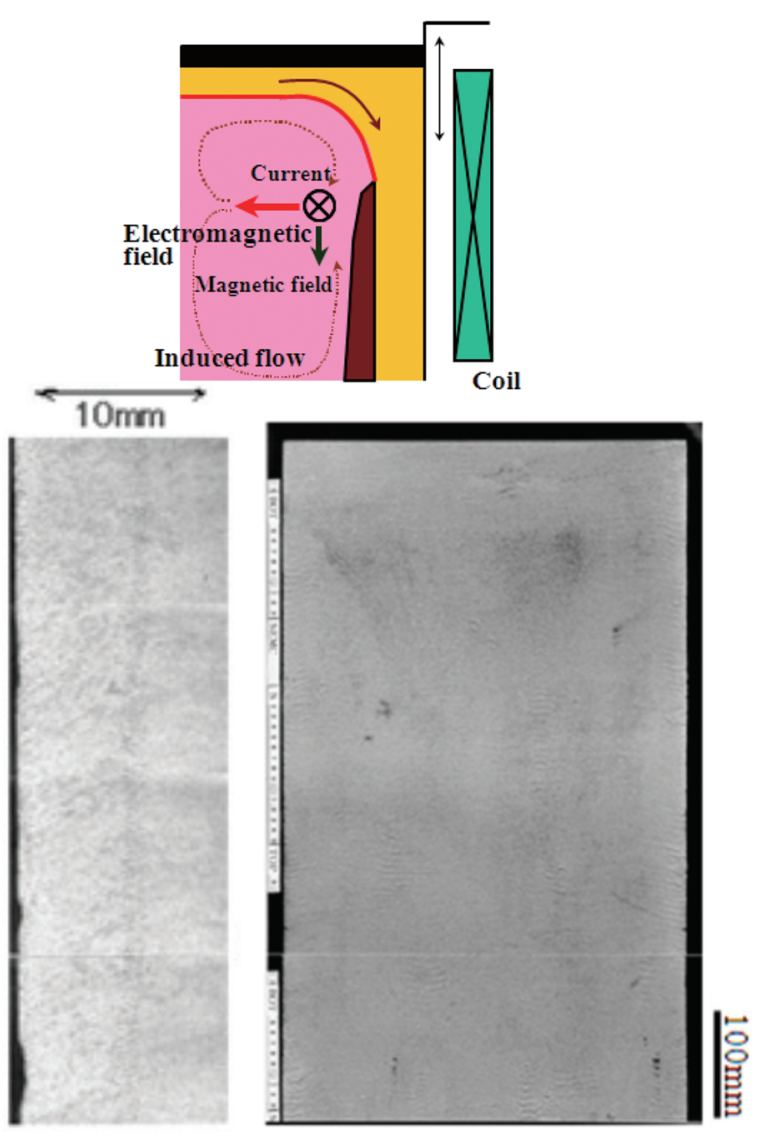

(b)

Fig. 12. Oscillation marks and hooks in steel slabs (a) without and (b) with EMC. Reprinted with permission from Ref. 91

improves the internal quality by lessening the centerline segregation and center porosity, as shown in Fig. 14.

The rotating flow across the solidification front due to the stirring fields can change the columnar dendrite growth directions, as the asymmetric concentration fields cause the dendrites to bend towards the flow direction. In addition, white bands and/or dark bands, indicating low solute concentration and high solute concentration, respectively, are caused by the cross flow across the solidification front due to nonuniform solute distribution, ${ }^{94}$ as shown in Fig. 13c.

\section{Control Steel Composition Distribution for Clad Steel Casting}

A level DC magnetic field (LMF) can be applied to create as-cast steel slabs with an outer layer of stainless steel and interior of carbon steel, ${ }^{98-100}$ as shown in Fig. 15. LMF employs a single ruler across the strand width to generate a horizontal rectangular-shaped static magnetic field across the mold width, located vertically between the port outlets of the two nozzles, as shown in Fig. 15a. The strong magnetic field produces a flow recirculation region above the field, which mainly prevents the molten stainless steel from exiting from the shallower submergence-depth nozzle from flowing below the ruler, as shown in Fig. 15b. Thus, this flow pattern results in stainless steel solidification only in the outer layer of the slab. At the same time, molten carbon steel from the deeper nozzle, located below the single-ruler field, flows only in the liquid pool below the ruler and solidifies as the interior of the clad steel slab. As shown in a horizontal crosssection macroetch of the microstructure (Fig. 15c) and in the nickel composition distribution (Fig. 15d), the strong field successfully prevents mixing of the two steel grades, producing a final product with a stainless-steel outer layer and a carbon-steel interior.

\section{SUMMARY AND CONCLUSION}

This article has reviewed solidification defects in continuous casting of steel and discussed the effects of electromagnetic fields including static, moving, 
and combined fields on the solidification related phenomena in the process. These solidification defects include:

- Meniscus freezing, hook formation, and slag infiltration problems are associated with slow or stagnant surface flows accompanying insufficient superheat transport to the meniscus re-
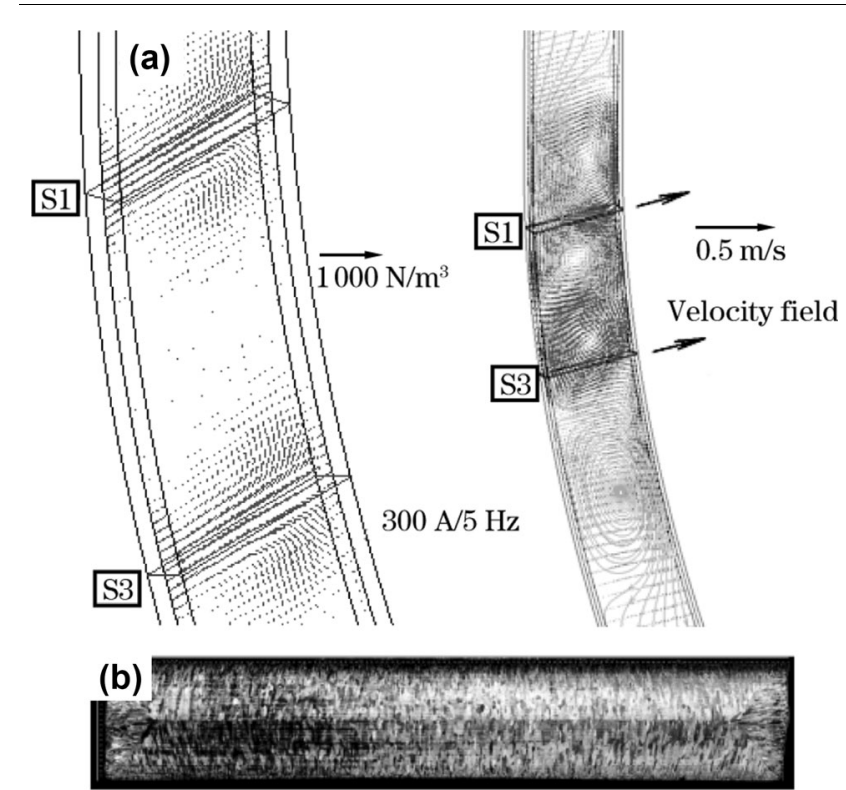

(c)

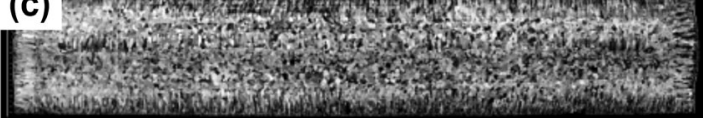

Fig. 13. (a) Flow pattern with SEMS and microstructure of nonoriented electrical steel in slab horizontal cross sections (b) without and (c) with SEMS (54\% equiaxed grains). Reprinted with permission from Ref. 94 gion, especially near the corners. Deep hooks are indirectly detrimental to steel quality due to their entrapment of particles into the initial shell.

- Particles including argon bubbles, entrained slag droplets, and alumina inclusions can be captured into the solidifying steel shell by hooks, between PDAS, or by engulfment of growing dendrites. They become surface or internal defects in the final product if they are captured too deeply to be removed by scale formation or scarfing.

- Deep oscillation marks, depressions, and other surface defects are caused by severe surface level fluctuations or by low meniscus temperature, which both depend on mold flow. They are detrimental to surface quality as they decrease heat transfer across the gap between the steel shell and the mold, leading to cracks and breakouts.

- Surface depressions and cracks form by different mechanisms involving many complex inter-related phenomena, including local flow disruptions and slag infiltration problems at the meniscus. They can be monitored by high-density online sensors, aided by analysis tools, which enable corrective actions.

- Breakouts are the most dangerous and costly defects in continuous casting. They often arise from shell thinning and crack formation just below the mold exit due to a depression that initiates at the meniscus due to a fluid flow problem.

- Macrosegregation is an important quality problem that is strongly affected by fluid flow. It is associated with shrinkage and porosity defects in the interior of as-cast product and depends on the grain structure.

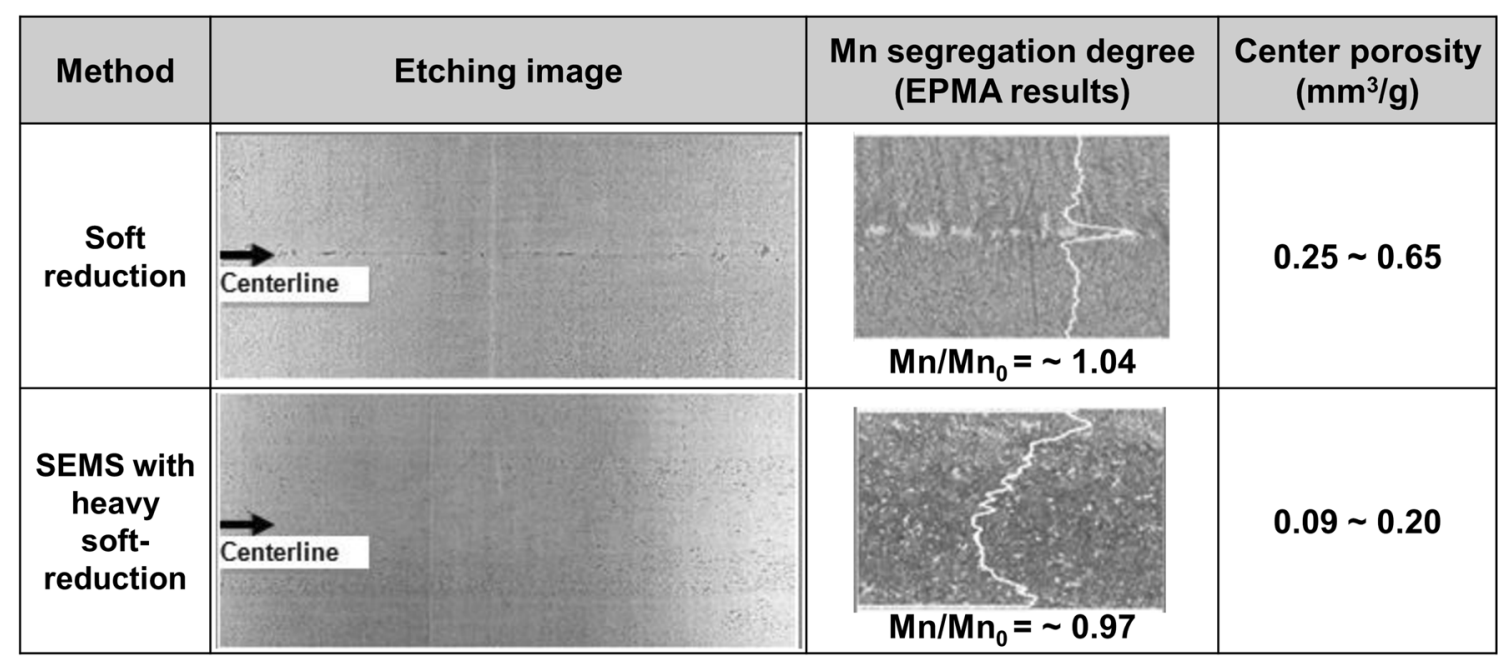

Fig. 14. Effects of SEMS with heavy soft-reduction on segregation and porosity defects. Reprinted with permission from Ref. 97 


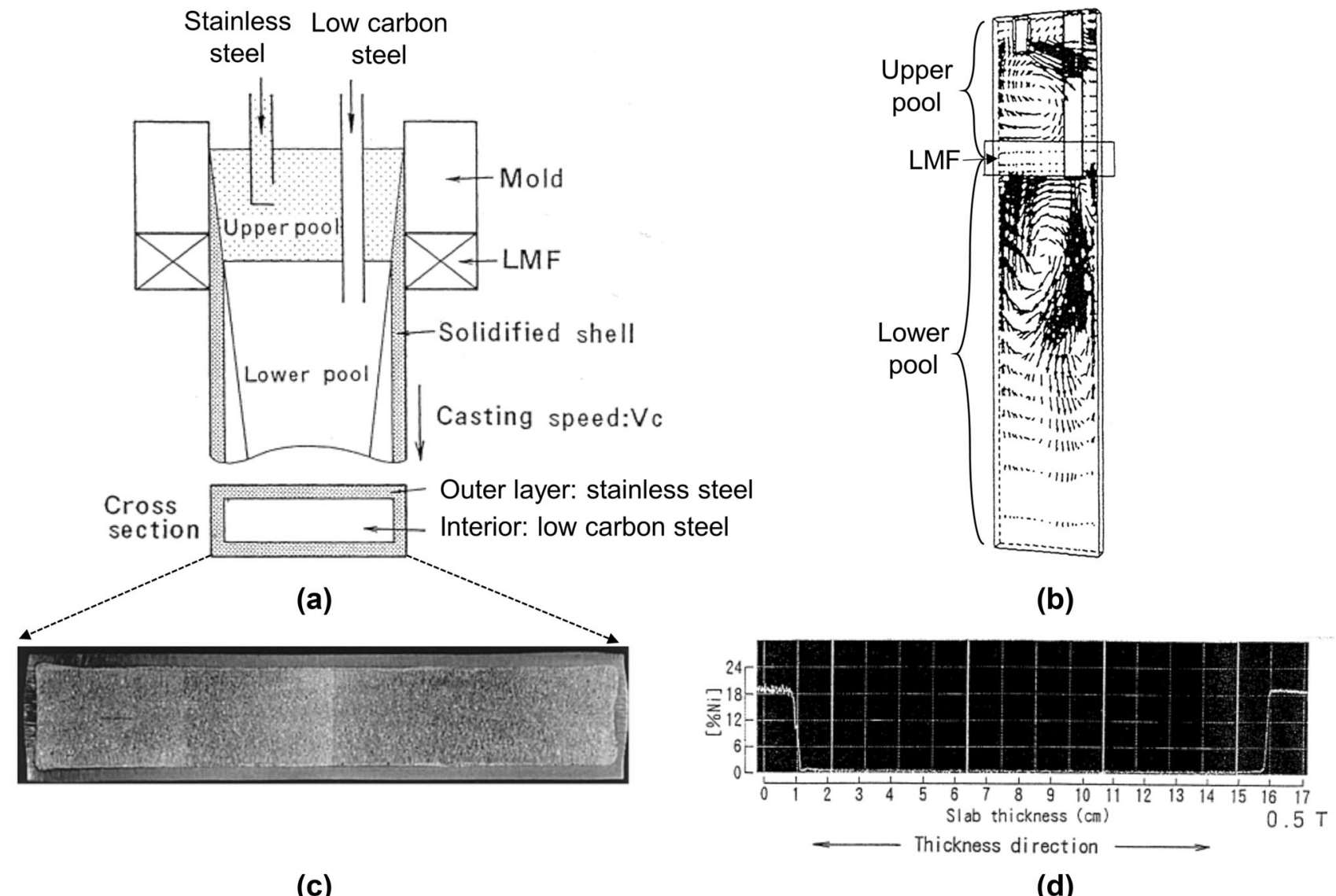

Fig. 15. (a) Schematic of clad steel casting and (b) flow patterns in the mold and strand region with LMF, (c) microstructure, and (d) nickel distribution in the clad steel slab. Reprinted with permission from Ref. 98

Electromagnetic systems affect the formation of these defects by controlling several important solidification phenomena, which suggest several practical considerations for their successful implementation:

- Static magnetic field systems, such as local electromagnetic braking (EMBr) and singleand double-ruler EMBr, control the mold flow pattern and its stability, which in turn controls superheat transport and initial solidification. Their effect strongly depends on the location of the field relative to the jet location.

- Electromagnetic casting (EMC) lessens contact between the solidifying steel shell and mold wall, resulting in shallower oscillation mark formation, which is better for the surface quality of ascast steel products.

- Electromagnetic rotating stirrer (EMRS), also called mold electromagnetic stirring (M-EMS), and strand EMS systems produce a rotating flow pattern that washes large particles away from the solidifying dendritic interface and facilitates a larger central region of equiaxed grains.

- Level DC magnetic field (LMF) systems can be employed to cast clad steel slabs by generating a strong static magnetic field across the strand width, which minimizes mixing between two different steel compositions flowing into the mold from two different-depth nozzles.

- When casting with large mold widths at low casting speed, meniscus freezing, deep hooks, and associated particle capture, deep oscillation marks due to low meniscus temperature and longitudinal cracks near the SEN and/or corner are expected quality problems, caused by slow/ stagnant surface flow and insufficient superheat transport to the meniscus during initial solidification. Thus, it is generally beneficial to direct the jets of molten steel entering the mold more upward. This can be aided by applying local electromagnetic braking (EMBr) and singleruler $\mathrm{EMBr}$ below the jet or a double-ruler $\mathrm{EMBr}$ with a stronger lower field, or an electromagnetic level accelerator (EMLA) or EMRS/MEMS for better mixing of the surface flow.

- When casting with smaller mold widths at high casting speed, excessive surface velocity and severe level fluctuations are potential problems causing slag entrainment and entrapment as well as accompanying particle capture, deep oscillation marks, surface depressions, shell thinning, cracks, and breakouts. To avoid these problems, the jets should generally be controlled 
to direct more downward, by applying a local or single-ruler EMBr field above the jet, doubleruler $\mathrm{EMBr}$ with a strong upper field, or electromagnetic level stabilizer (EMLS).

- These general guidelines may need adjustment according to the nozzle geometry and other casting conditions, such as argon injection rate and nozzle submergence depth.

\section{FUTURE WORK}

Although electromagnetic systems and understanding of them are improving, more work is needed to implement automated flow control systems that can respond to changing flow conditions and adjust in real time to avoid quality problems. Realizing this potential will require improvements to advanced sensors, improved understanding of defect formation, and improved analysis of the sensor data to enable easy visualization of the problems and to take appropriate corrective action.

\section{ACKNOWLEDGEMENTS}

Support from the Continuous Casting Center at Colorado School of Mines, the Continuous Casting Consortium at University of Illinois at UrbanaChampaign, and the National Science Foundation GOALI Grant (Grant No. CMMI 18-08731) are gratefully acknowledged. Provision of Fluent licenses through the Ansys Inc. academic partnership program is much appreciated.

\section{REFERENCES}

1. World Steel Association, Steel Statistical Yearbook 2018 (Brussels: World Steel Association, 2018), pp. 9-12.

2. B.G. Thomas, Continuous Casting: Complex Models, in The Encyclopedia of Advanced Materials: Science and Technology, eds. by K.H.J. Buschow, R. Cahn, M. Flemings, B. Ilschner, E.J. Kramer, and S. Mahajan (J. Dantzig, subject ed.), (Elsevier Science Ltd., Oxford, 2001), vol. 2, pp. 15991609 .

3. K.C. Mills, P. Ramirez-Lopez, P.D. Lee, B. Santillana, B.G. Thomas, and R. Morales, Ironmak. Steelmak. 41, 242 (2014).

4. B.G. Thomas, Steel Res. Int. 89, 1700312 (2018).

5. B.G. Thomas, Continuous Casting, in Yearbook of Science and Technology (New York: McGraw-Hill, 2004), pp. 62-65.

6. K.C. Mills, S. Karagadde, P.D. Lee, L. Yuan, and F. Shahbazian, ISIJ Int. 56, 264 (2016).

7. K.C. Mills, S. Karagadde, P.D. Lee, L. Yuan, and F. Shahbazian, ISIJ Int. 56, 274 (2016).

8. B.G. Thomas, M.A. Wells, and D. Li, in Sensors, Sampling, and Simulation for Process Control, eds. by B.G. Thomas, J.A. Yurko, and L. Zhang (Wiley, Hoboken, 2011), pp. 119126.

9. T. Spierings, A. Kamperman, H. Hengeveld, J. Kromhout, and E. Dekker, in Proc. AISTech 2017 (AIST, Warrendale, 2017), pp. 1-9.

10. G. Hedin, A. Kamperman, M. Seden, K. Frojdh, and J. Pejnefors, in Proc. SCANMET V: 5th International Conference on Process Development in Iron and Steelmaking (Swerea MEFOS, Luleå, 2016).

11. M. R. Ridolfi, B. G. Thomas, G. Li, and U. Della Foglia, in Continuous Casting (Iron and Steel Society, Warrendale, 1997), vol. 9, pp. 259-269; reprinted from La Revue de Metallurgie - CIT 91(2), 609 (1994).
12. B.G. Thomas and W.R. Storkman, in Modeling and Control of Casting and Welding Processes - IV, eds. by A.F. Giamei and G.J. Abbaschian (The Metallurgical Society, Warrendale, 1988), pp. 287-297; in Engineering Foundation Conference, (Palm Coast, FL, April 17-22, 1988).

13. K. Zheng, B. Petrus, B.G. Thomas, and J. Bentsman, in AISTech 2007, Steelmaking Conference Proc., (AIST, Warrendale, 2007), vol. 1, pp. 1-16, (Indianapolis, IN, May 7-10, 2007).

14. M. Raudenský, A.A. Tseng, J. Horský, and J. Komínek, Metall. Res. Technol. 113, 509 (2016).

15. R. Thome and K. Harste, ISIJ Int. 46, 1839 (2006).

16. M.O. El-Bealy, Mater. Sci. Appl. 5, 724 (2014).

17. Z. Chen, W. Drennan, B.G. Thomas, J. Bentsman, in Proc. AISTech 2019 (AIST, Warrendale, 2019), pp. 2075-2083, (Pittsburgh, PA., May 6-9, 2019).

18. S.-M. Cho and B.G. Thomas, Metals 9, 471 (2019).

19. M. Iguchi, J. Yoshida, T. Shimizu, and Y. Mizuno, ISIJ Int. 40, 685 (2000).

20. R. Hagemann, R. Schwarze, H.P. Heller, and P.R. Scheller, Metall. Mater. Trans. B 44B, 80 (2013).

21. J. Sengupta, B.G. Thomas, H. Shin, G. Lee, and S. Kim, Metall. Mater. Trans. A 37A, 1597 (2006).

22. J. Sengupta, H.-J. Shin, B.G. Thomas, and S.-H. Kim, Acta Mater. 54, 1165 (2006).

23. G.-G. Lee, B.G. Thomas, H.-J. Shin, S.-K. Baek, C.-H. Choi, D.-S. Kim, S.-J. Yu, and S.-H. Kim, Acta Mater. 55, 6705 (2007).

24. Y. Meng and B.G. Thomas, Metall. Mater. Trans. B 34, 685 (2003).

25. G.D. Lawson, S.C. Sander, W.H. Emling, A. Moitra, and B.G. Thomas, in 77th Steelmaking Conference Proceedings, (Iron and Steel Society, Warrendale, 1994), vol. 77, pp. 329-336.

26. M.L.S. Zappulla, S.-M. Cho, and B.G. Thomas, Steel Res. Int. 90, 1800540 (2019).

27. B.G. Thomas, R. O'Malley, T. Shi, Y. Meng, D. Creech, and D. Stone, in Proc. Modeling of Casting, Welding, and Advanced Solidification Processes (MCWASP) IX (Shaker Verlag GmbH, Aachen, 2000), pp. 769-776.

28. K.G. Rackers and B.G. Thomas, in Continuous Casting Vol. 10 Tundish Operations (Iron and Steel Society, Warrendale, 2003), pp. 264-274.

29. L.C. Hibbeler and B.G. Thomas, Iron Steel Technol. 10, 121 (2013).

30. S.-M. Cho, B.G. Thomas, and S.-H. Kim, Metall. Mater. Trans. B 50B, 52 (2019).

31. L. Zhang, S. Yang, K. Cai, J. Li, X. Wan, and B.G. Thomas, Metall. Mater. Trans. B 38, 63 (2007).

32. S-M. Cho, M. Liang, H. Olia, L. Das, and B.G. Thomas, in TMS 2020 149th Annual Meeting \& Exhibition Supplemental Proceedings (The Minerals, Metals \& Materials Society, Warrendale, 2020), pp. 1161-1173.

33. B.G. Thomas, Q. Yuan, S. Mahmood, R. Liu, and R. Chaudhary, Metall. Mater. Trans. B 45, 22 (2014).

34. K. Jin, B.G. Thomas, and X. Ruan, Metall. Mater. Trans. B 47B, 548 (2016).

35. M. Liang, S.-M. Cho, H. Olia, L. Das, X. Ruan, and B.G. Thomas, in Proc. AISTech 2019 Conf. (AIST, Warrendale, 2019), pp. 2219-2231, (Pittsburgh, PA, May 6-9, 2019).

36. Y. Miki and S. Takeuchi, Iron Steel Inst. Jpn. 43, 1548 (2003).

37. L. Zhang and B.G. Thomas, ISIJ Int. 43, 271 (2003).

38. G.-G. Lee and B.G. Thomas, in Continuous Casting Consortium Report (University of Illinois, Urbana, 2007).

39. J. Sengupta, C. Ojeda, and B.G. Thomas, Int. J. Cast Met. Rese. 22, 8 (2009).

40. A. Badri, T.T. Natarajan, C.C. Snyder, K.D. Powers, F.J. Mannion, and A.W. Cramb, Metall. Mater. Trans. B 36, 355 (2005).

41. A. Badri, T.T. Natarajan, C.C. Snyder, K.D. Powers, F.J. Mannion, M. Byrne, and A.W. Cramb, Metall. Mater. Trans. B 36, 373 (2005). 
42. A.S.M. Jonayat and B.G. Thomas, Metall. Mater. Trans. B 45, 1842 (2014).

43. X. Yan, A.S.M. Jonayat, and B.G. Thomas, in Proc. TMS Annual Meeting, Frontiers in Solidification: An MPMD Symposium in Honor of Michel Rappaz (The Minerals, Metals, and Materials Society, Warrendale, 2016), pp. 181186, (Nashville, TN, Mar. 14-18, 2016).

44. B.G. Thomas, D. Lui, and B. Ho, in Sensors and Modeling in Materials Processing: Techniques and Applications, ed. by S. Viswanathan, R.G. Reddy, and J.C. Malas (The Minerals, Metals, and Materials Society, Warrendale, 1997), pp. 117-142.

45. B. Santillana, B.G. Thomas, D.W. van der Plas, D. Ruvalcaba, and A.J.C. Burghardt, in Proceedings of the 2015 International Symposium on Liquid Metal Processing and Casting, eds. by Abdellah Kharicha, R. Mark Ward, H. Holzgruber, and M. Wu, (IOP Publishing, Bristol, 2015), pp. 539-547.

46. J.K. Brimacombe and K. Sorimachi, Metall. Trans. B 8B, 489 (1977).

47. J. Sengupta and B.G. Thomas, JOMe (Journal of Metals-Electronic Edition), December 2006. https://www. tms.org/pubs/journals/JOM/0612/Sengupta/Sengupta-0612 .html. Accessed 6 July 2020.

48. B.G. Thomas, A. Moitra, and R. McDavid, Iron Steelmak. (ISS Trans.) 23, 57 (1996).

49. B.G. Thomas, A. Moitra, and H. Zhu, in Proc. Modeling of Casting, Welding, and Advanced Solidification Processes VII, (The Minerals, Metals \& Materials Society, Warrendale, 1995), pp. 241-248, (London, England, Sept. 10-15, 1995).

50. M.L.S. Zappulla and B.G. Thomas, in THERMEC' 2018. (Paris, France, July 2018).

51. M.L.S. Zappulla, S.-M. Cho, S. Koric, H.-J. Lee, S.-H. Kim, and B.G. Thomas, J. Mater. Process. Technol. 278, 116469 (2020).

52. M.L.S. Zappulla, Ph.D. Thesis, Colorado School of Mines (2020).

53. F. He, L. Zhou, and Z.-H. Deng, J. Process Control 29, 1 (2015).

54. M.L.S. Zappulla and B.G. Thomas, U.S. Provisional Patent Application No. 62/797,582, January 28, 2019; U.S. NonProvisional Patent Application filed January 28 (2020).

55. B.G. Thomas, R. O'Malley, and D. Stone, in Proc. Modeling of Casting, Welding, and Advanced Solidification Processes VIII, eds. by B. G. Thomas and C. Beckermann (TMS, Warrendale, 1998), pp. 1185-1199.

56. B. Santillana, B. G. Thomas, G. Botman, and E. Dekker, in Proc. 7th European Continuous-Casting Conference, 2011, MetTec InSteelCon (Stahlinstitut VDEh, Düsseldorf, 2011), pp. 1-9, (Dusseldorf, Germany, June 27-July 1, 2011).

57. J. Iwasaki and B. G. Thomas, in Supplemental Proceedings: Volume 2: Materials Properties, Characterization, and Modeling (TMS, Warrendale, 2012), pp. 355-362; in TMS Annual Meeting, Defects and Properties of Cast Metals Symposium (Orlando, FL, Mar. 12-15, 2012).

58. Y.-M. Won and B.G. Thomas, Metall. Mater. Trans. A 32A, 1755 (2001).

59. T. Brune, K. Kortzak, D. Senk, N. Reuther, and M. Schäperkötter, Steel Res. Int. 86, 33 (2015).

60. S.K. Choudhary, S. Ganguly, A. Sengupta, and V. Sharma, J. Mater. Process. Technol. 243, 312 (2017).

61. S. Kollberg, P. M. Lofgren, and P. Hanley, in Proc. AISTech 2004 (AIST, Warrendale, 2004), pp. 977-984, (Nashville, TN, USA, 15-17 September 2004).

62. M. Zeze, H. Harada, E. Takeuchi, and T. Ishii, in Proc. the 76th Steelmaking Conference (Iron and Steel Society, Warrendale, 1993), pp. 267-272, (Dallas, TX, USA, 28-31 March 1993).

63. S.-M. Cho, B.G. Thomas, and S.-H. Kim, Metall. Mater. Trans. B 47B, 3080 (2016).

64. S.-M. Cho, S.-H. Kim, and B.G. Thomas, ISIJ Int. 54, 855 (2014).
65. P.H. Dauby, Revue de Métallurgie 109, 113 (2012).

66. S. Kunstreich and P.H. Dauby, Ironmak. Steelmak. 32, 80 (2005).

67. S. Kunstreich, Rev. Met. Paris 100, 1043 (2003).

68. J. Nakashima, J. Fukuda, A. Kiyose, T. Kawase, Y. Ohtani, and M. Doki, Nippon Steel Tech. Rep. 86, 61 (2002).

69. K. Fujisaki, IEEE Trans. Ind. Appl. 37, 1098 (2001).

70. M. Sedén, N. Jacobson, A. Lehman, and J.-E. Eriksson, in Proc. the 8th European Continuous Casting Conference (Graz, Austria, 23-26 June 2014), pp. 588-569.

71. S. Kunstreich, Rev. Met. Paris 100, 395 (2003).

72. S. Kunstreich, Millenn. Steel 122 (2008).

73. X. Huang, B.G. Thomas, and F.M. Najjar, Metal. Trans. B 23B, 339 (1992).

74. B. Zhao, S.P. Vanka, and B.G. Thomas, Int. J. Heat Fluid Flow 26, 105 (2005).

75. H. Todoroki, A.W. Cramb, R. Lertarom, and T. Suzuki, ISS Trans., Iron Steelmak. 26, 57 (1999).

76. Y. Wang and L. Zhang, Metall. Mater. Trans. B 42B, 1319 (2011).

77. D.-S. Kim, W.-S. Kim, and K.-H. Cho, ISIJ Int. 40, 670 (2000).

78. K. Cukierski and B.G. Thomas, Metall. Mater. Trans. B 38B, 94 (2008).

79. K. Takatani, K. Nakai, N. Kasai, T. Watanabe, and H. Nakajima, ISIJ Int. 29, 1063 (1989).

80. S. Wang, X. Zhang, L. Zhang, and Q. Wang, Steel Res. Int. 89, 1800263 (2018).

81. K. Okazawa, T. Toh, J. Fukuda, T. Kawase, and M. Toki, ISIJ Int. 41, 851 (2001).

82. N. Kubo, J. Kubota, M. Suzuki, and T. Ishii, ISIJ Int. 47 , 988 (2007).

83. J.-F. Domgin, M. Anderhuber, M.D. Doncker, and A.D. Paepe, J. Manuf. Sci. Prod. 15, 105 (2015).

84. N. Kubo, T. Ishii, J. Kubota, and T. Ikagawa, ISIJ Int. 44 556 (2004).

85. K. Jin, S.P. Vanka, and B.G. Thomas, Metall. Mater. Trans. B 49B, 1360 (2018).

86. T. Teshima, M. Osame, K. Okimoto, and Y. Nimura, in Proceedings of 71 Steelmaking Conference (The Iron and Steel Society, Warrendale, 1988), pp. 111-118.

87. H. Nakamura, S. Kohira, J. Kubota, T. Kondo, M. Suzuki, and Y. Shiratani, in Steelmaking Conference Proceedings (The Iron and Steel Society, Warrendale, 1992), pp. 409415 .

88. J. Kubota, K. Okimoto, A. Shirayama, and H. Murakami, in Steelmaking Conference Proceedings (The Iron and Steel Society, Warrendale, 1991), pp. 233-241.

89. B.G. Thomas, R. Singh, S.P. Vanka, K. Timmel, S. Eckert, and G. Gerbeth, J. Manuf. Sci. Prod. 15, 9 (2015).

90. S.-W. Han, H.-J. Cho, S.-Y. Jin, M. Sedén, I.-B. Lee, and I. Sohn, Metall. Mater. Trans. B 49B, 2757 (2018).

91. M. Tani, M. Zeze, T. Toh, K. Tsunenari, K. Umetsu, K. Hayashi, K. Tanaka, and S. Fukunaga, Nippon Steel Tech. Rep. 104, 62 (2013).

92. S. Kittaka, T. Fukuokaya, Y. Maruki, and T. Kanki, Nippon Steel Tech. Rep. 87, 70 (2003).

93. Y. Xu, X.-J. Xu, Z. Li, T. Wang, A.-Y. Deng, and E.-G. Wang, High Temp. Mater. Proc. 36, 339 (2017).

94. J. Gong, H.-P. Liu, X.-H. Wang, and Y.-P. Bao, J. Iron. Steel Res. Int. 22, 414 (2015).

95. N. El-Kaddah and T. T. Natarajan, in Proceedings of the Second International Conference on CFD in the Mineral and Process Industries, (CSIRO, Canberra, 1999), pp. 339344, (Melbourne, Australia, 6-8 December, 1999).

96. H. Shibata, S. Itoyama, Y. Kishimoto, S. Takeuchi, and H. Sekiguchi, ISIJ Int. 46, 921 (2006).

97. G. H. Kim, S. H. Kwon, Y. M. Won, and C. H. Lee, in Proceedings of the 8th International Conference on Electromagnetic Processing of Materials (EPM 2015) (SIMaP, Gières, 2015), pp. 1-3, (Cannes, France, 12-16 October 2015).

98. H. Harada, E. Takeuchi, M. Zeze, and H. Tanaka, Appl. Math. Modell. 22, 873 (1998). 
99. E. Takeuchi, H. Harada, H. Tanaka, and H. Kajioka, in Magnetohydrodynamics in Process Metallurgy (The Minerals, Metals and Materials Society, Warrendale, 1992), pp. 261-266.

100. M. Zeze, H. Harada, E. Takeuchi, and T. Ishii, Iron Steelmak. 20, 53 (1993).
Publisher's Note Springer Nature remains neutral with regard to jurisdictional claims in published maps and institutional affiliations. 